\title{
MOCVD-Grown Dilute Nitride Type II Quantum Wells
}

\author{
L. J. Mawst, Senior Member, IEEE, Juno Yu-Ting Huang, Student Member, IEEE, D. P. Xu, Jeng-Ya Yeh, \\ Gene Tsvid, Thomas F. Kuech, Member, IEEE, and Nelson Tansu
}

(Invited Paper)

\begin{abstract}
Dilute nitride Ga(In)NAs/GaAsSb "W" type II quantum wells on GaAs substrates have been grown by metal-organic chemical vapor deposition (MOCVD). Design studies underscore the importance of nitrogen incorporation to extend the emission wavelength into the $1.5 \mu \mathrm{m}$ region as well as increase the electron confinement, given the material strain relaxation limitations. These studies also indicate that the Sb content of the $\mathrm{GaAs}_{1-x} \mathrm{Sb}_{x}$ hole well is required to be greater than $x \sim 0.2$, to provide adequate hole confinement (i.e., $\Delta E_{v}>150 \mathrm{meV}$ ). Photoluminescence (PL) and electroluminescence (EL) studies are used to characterize the optical transitions and compare with a ten-band $k . p$ simulation. We find that the lowest energy type II transition observed is in good agreement with theory. Preliminary results are presented on diode lasers with two- and three-stage "W"-active regions that exhibit emission that is blue-shifted from the PL, due to charge separation and carrier band-filling of higher energy transitions. Further structure optimization, including multiple-stage (eight to ten Wstages) active regions is required to lower the threshold carrier density and minimize carrier band-filling and built-in electric field effects resulting from charge separation. Dilute nitride materials, such as $\mathrm{GaAs}_{1-y-z} \mathrm{Sb}_{y} \mathrm{~N}_{z} / \mathrm{InP}$, are also under development offering potential for wavelength extension into the mid-IR employing InP substrates.
\end{abstract}

Index Terms-GaAs, GaAsSb, GaInNAs, mid-IR, semiconductor lasers, ten-band $k . p$ Hamiltonian, type II.

\section{INTRODUCTION}

$\mathbf{H}$ IGH-PERFORMANCE diode lasers emitting in the eyesafe wavelength regions $(\lambda>1.5 \mu \mathrm{m})$ generally exhibit poor performance compared with shorter wavelength, near-IR $(\lambda=0.8-0.98 \mu \mathrm{m})$ devices. This fact stems from the stronger device temperature sensitivity as a result of the increased thermally

Manuscript received December 12, 2007; revised January 8, 2008. This work was supported in part by the Department of Defense Multidiciplinary University Research Initiative (ARO MURI) W911NF-05-1-0262 (Dr. John Prater) and in part by the National Science Foundation (NSF) under Grant ECS-0355442.

L. J. Mawst, J. Y. T. Huang, D. P. Xu, J. Y. Yeh, and G. Tsvid are with the Department of Electrical and Computer Engineering, University of Wisconsin-Madison, Madison, WI 53706-1691 USA (e-mail: mawst@engr. wisc.edu; yuting@cae.wisc.edu; xdapeng@wisc.edu; jyeh1207@gmail.com; tsvid@cae.wisc.edu).

T. F. Kuech is with the Department of Chemical and Biological Engineering, University of Wisconsin-Madison, Madison, WI 53706-1691 USA (e-mail: kuech@engr.wisc.edu).

N. Tansu is with the Center for Optical Technologies, Department of Electrical and Computer Engineering, Lehigh University, Bethlehem, PA 18015 USA (e-mail: tansu@lehigh.edu).

Color versions of one or more of the figures in this paper are available online at http://ieeexplore.ieee.org.

Digital Object Identifier 10.1109/JSTQE.2008.918105 activated recombination pathways, higher optical losses, and active layer carrier leakage. Much effort has been directed toward achieving $1.3-1.55 \mu \mathrm{m}$ emission using various types of active material on GaAs substrates, due to the potential advantages offered from extending the emission wavelength of GaAs-based lasers. The benefits of GaAs-based technology include the following: the large band offsets of AlGaAs-based materials can provide strong carrier confinement as well as ease the implementation of the active regions into vertical-cavity surface-emitting lasers (VCSELs), allowing high-index contrast AlAs/GaAs distributed Bragg reflectors (DBRs) to be utilized. Due to strain relaxation limitations, laser emission wavelengths longer than $\sim 1.24 \mu \mathrm{m}$ from GaInAs quantum wells (QWs) require the use of InP substrates [1]-[4]. (Ga)InAs quantum dots (QDs) have been pursued by many different groups with various degrees of successes for wavelengths in the $1.3 \mu \mathrm{m}$ region [5]-[7]. QD active lasers exhibit extremely low transparency current densities because of the small active volume. However, low modal gain, high temperature sensitivity, poor modulation response, and wavelength extension to $1.55 \mu \mathrm{m}$ are still issues under active development by many groups. Other alternatives for 1.3-1.55 $\mu \mathrm{m}$ emission from GaAs-based active regions include the use of GaAsSb materials [8]-[10].

An attractive approach for achieving long-wavelength laser emission on GaAs substrates is the use of highly strained GaInAs [1]-[4], [11], [12] or GaInNAs [13]-[20] QWs. The use of highly strained (compressive) GaInAs QW active lasers to extend the emission wavelength beyond $1.20 \mu \mathrm{m}$ was pioneered by S. Sato and Satoh [1] and Koyama and coworkers [21], [22]. GaAsP tensile-strained barriers have also been implemented to strain-compensate the GaInAs QWs [2], [23]. Extremely low threshold current densities have been reported from highly strained GaInAs QW lasers in the $1.2 \mu \mathrm{m}$ wavelength region [1]-[4], [21]-[25]. The significant reduction in the bandgap of the GaInNAs materials, pioneered by Kondow et al. [13], due to the presence of the $\mathrm{N}$, is also followed by a reduction in the compressive strain of the material. Since then, many promising results have been demonstrated for $1.3 \mu \mathrm{m}$ GaInNAsactive lasers by both molecular beam epitaxy (MBE) and metalorganic chemical vapor deposition (MOCVD) [13]-[20].

One of the challenges in growing GaInNAs QW lasers by MOCVD is the difficulty of incorporating $\mathrm{N}$ into the GaInAs QW, while maintaining a high-optical-quality film. The low purity of the N-precursor used in MOCVD [U-dimethylhydrazine (U-DMHy)] is suspected as a possible reason for the low optical 


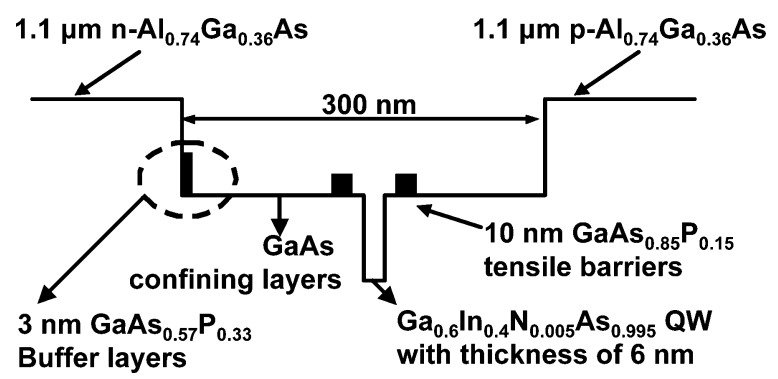

Fig. 1. Schematic diagram of single GaInNAs QW $(\lambda=1.30 \mu \mathrm{m})$ laser structure.

quality of MOCVD-grown GaInNAs QWs. Also, in order to incorporate sufficient $\mathrm{N}$ into the GaInNAs QW, very large $[\mathrm{DMHy} / \mathrm{V}$ (typically $>0.961$ ) is required. Due to the high cost and the low purity of the DMHy precursor, lowering the $\left[\mathrm{AsH}_{3}\right] / \mathrm{III}$ to achieve large [DMHy]/V would be the preferable option for increasing the DMHy flow. As a result, a large $[\mathrm{DMHy}] / \mathrm{V}$ ratio requires the $\left[\mathrm{AsH}_{3}\right] / \mathrm{III}$ ratio to be rather low. As the $\left[\mathrm{AsH}_{3}\right] / \mathrm{III}$ ratio is reduced, the luminescence of the GaInAs QW reduces rapidly for low $\left[\mathrm{AsH}_{3}\right] / \mathrm{III}$ (below 15-20) [25]. Nevertheless, high-performance MOCVD-GaInNAs QW lasers with $\mathrm{AsH}_{3}$ as the As-precursor have been reported in the $1.3 \mu \mathrm{m}$ wavelength region [19], [26].

In our previous work, GaInNAs QW lasers with an In content of $40 \%$ and $\mathrm{N}$ content of only $\sim 0.5 \%$ have been realized with record low threshold current densities of only $210 \mathrm{~A} / \mathrm{cm}^{2}$ at an emission wavelength of $1295 \mathrm{~nm}$ [19], [26]. The type I QW laser structures, shown in Fig. 1, utilized strain compensating $7.5 \mathrm{~nm} \mathrm{GaAs} \mathrm{n}_{0.85} \mathrm{P}_{0.15}$ tensile strain layers surrounding the highly compressively strained ( $\Delta a / a \sim 2.7 \%$ ) GaInNAs well. The separate confinement heterostructure $(\mathrm{SCH})$ consists of a $300 \mathrm{~nm}$ undoped $\mathrm{GaAs}$ region, with both $\mathrm{n}$ - and p-type cladding layers consisting of 1.1- $\mu$ m-thick $\mathrm{Al}_{0.75} \mathrm{Ga}_{0.25}$ As layers. Similar structures, although with increased $\mathrm{N}$ content $(N \sim 1.0 \%)$ in the active region, have been achieved among the highest performance GaInNAs lasers reported to date for lasers emitting up to $1.38 \mu \mathrm{m}$ grown by MOCVD [27], [28]. However, an "N-penalty" is clearly evident for MOCVD-grown GaInNAs QW lasers, i.e., increased $\mathrm{N}$ content leads to increased monomolecular recombination, leading to a higher threshold current density [28]. The addition of nitrogen to GaInAs has been linked to a decrease in the radiative efficiency of the material [29]. Due to strain limitations, higher In content cannot be implemented. Thus, if we restrict the $\mathrm{N}$ content to a reasonable range $<1.5-2.0 \%$, the emission wavelength is limited to below $\sim 1.4 \mu \mathrm{m}$ [27], [28].

Extending the emission wavelength of MOCVD-grown GaInNAs-active lasers to $1.55 \mu \mathrm{m}$ and beyond remains a considerable challenge. The extension of emission wavelength further by the introduction of higher $\mathrm{N}$ content leads to increased monomolecular recombination and a resulting higher threshold current density. Alternative approaches to increase the emission wavelength include the introduction of Sb into GaInNAs [30], [31]. However, this approach has yielded promising results near $\lambda \sim 1.5 \mu \mathrm{m}$ only for MBE-grown GaInNAsSb-active devices.
Furthermore, extending the emission wavelengths much beyond $1.5 \mu \mathrm{m}$ with this approach is challenging due to the high strain of the QW employed.

New dilute-nitride-based active layer designs hold potential to enable long-wavelength lasers on $\operatorname{GaAs}(\lambda>1.5 \mu \mathrm{m})$ and $\operatorname{InP}(\lambda>2.0 \mu \mathrm{m})$ substrates. Furthermore, such structures will allow for the study of carrier recombination mechanisms in spatially indirect transition dilute nitride type II QWs. Recently, we proposed a novel approach with a $\mathrm{Ga}$ (In)NAs$\mathrm{GaAsSb}$ type II QW active region for realizing GaAs-based diode lasers with emission wavelengths beyond $\lambda=1.5 \mu \mathrm{m}$ [32], [33]. This approach utilizes the type II band alignment between $\mathrm{Ga}(\mathrm{In}) \mathrm{NAs}$ and GaAsSb. Dilute nitride type II QWs based on In(Ga)AsN/GaAsSb [34] and GaAsSbN/GaAsSb [35] materials grown on InP substrates have also been proposed to achieve mid-IR emission (2-4 $\mu \mathrm{m})$.

Here, we describe a comprehensive design analysis and experimental studies on the properties of MOCVD-grown dilute nitride type II QW materials. Preliminary studies on the implementation of diode laser device structures on GaAs substrates indicate that optical gain is significantly lower than expected from theory, presumably due to the large nonradiative recombination present in these materials. Both GaInNAs/GaAsSb and GaNAs/GaAsSb-active regions demonstrate PL emission in the $\lambda=1.5 \mu \mathrm{m}$ region on GaAs substrates, although further optimization of the growth of these highly strained structures is necessary to produce sufficiently high gain (at low carrier densities) for RT diode laser operation. Diode laser structures incorporating two- and three-stage W-structure GaInNAs/GaAsSb-active regions are found to exhibit significant blue-shift in emission wavelength with increased carrier injection. Laser structure optimization includes maximizing the electron-hole wave function overlap, employing increased Sb content in the hole well for strong hole confinement, improving the optical properties of the dilute nitride materials through thermal annealing, and employing multiple-stage (eight to ten stages) active regions to provide sufficient gain at long wavelength for diode laser applications. Based on strain limitations, wavelength extension into the mid-IR $(\lambda>2 \mu \mathrm{m})$ requires the use of new dilute nitride materials, such as GaAsSbN, on InP substrates.

\section{TyPE II GaInNAs/GaAsSb QWs on GaAs SubSTRATE: DESIGN ISSUES}

Type II W-structure QWs, first proposed on GaSb substrates [36], exhibit emission over a wide wavelength range $(\lambda=3-6 \mu \mathrm{m})$ within the mid-IR spectral region [37]. Optically pumped InAs/InGaSb/InAs type II QW lasers have demonstrated high conversion efficiency in the 2.4-9.3 $\mu \mathrm{m}$ wavelength range, although room-temperature $\mathrm{CW}$ operation has not yet been achieved [38]. Recently, GaSb-based type II QW lasers have demonstrated $\lambda=3.4 \mu \mathrm{m}$ emission with a maximum CW operating temperature of $230 \mathrm{~K}$ [39]. GaAs-based type II QWs that employ strained GaInAs/GaAsSb-active regions have also been reported previously, as a means to extend the emission wavelength of GaAs-based sources into the telecommunication range $(\lambda=1.3-1.55 \mu \mathrm{m})$ [40]-[42]. The 


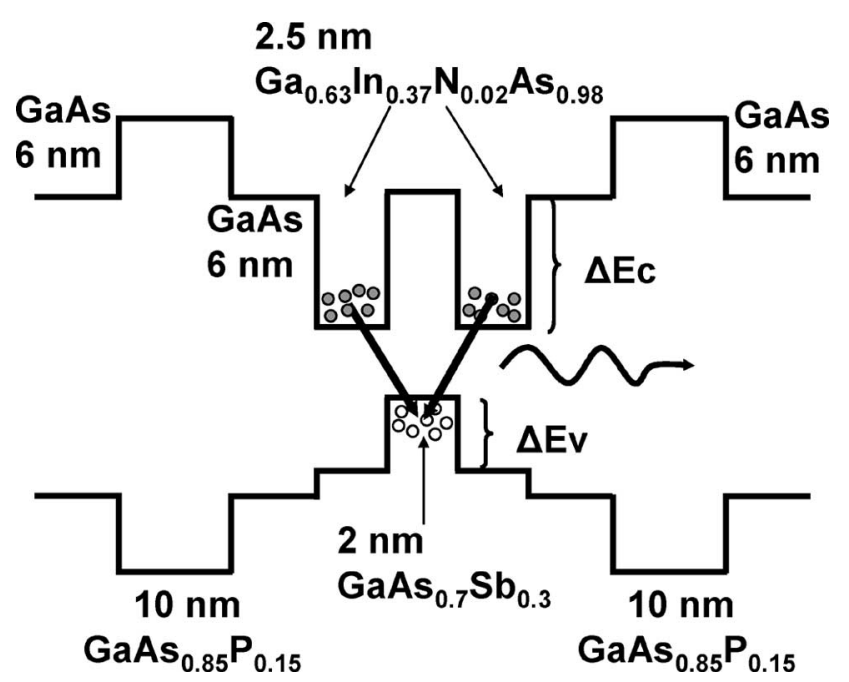

Fig. 2. Schematic band diagram of the "W" type II QW, with GaAsP barriers for strain compensation. Three stages of the "W" structure are used for the laser active region.



Fig. 3. Simulated energy band diagrams for a fixed strain $(\Delta a / a=-2.15 \%)$ of GaInAs and GaInNAs layers of sample A $\left(\mathrm{Ga}_{0.7} \mathrm{In}_{0.3} \mathrm{As} / \mathrm{GaAs}_{0.7} \mathrm{Sb}_{0.3}\right)$ and sample $\mathrm{B}\left(\mathrm{Ga}_{0.68} \mathrm{In}_{0.32} \mathrm{~N}_{0.005} \mathrm{As}_{0.995} / \mathrm{GaAs}_{0.7} \mathrm{Sb}_{0.3}\right)$ of $2.5 \mathrm{~nm}$ in each QW layer and with $6 \mathrm{~nm} \mathrm{GaAs}_{0.7} \mathrm{P}_{0.3}$ barriers surrounding each W-stage.

addition of nitrogen into the electron wells of such structures would allow for additional wavelength extension. Design studies indicate that a multiple-stage GaInNAs-GaAsSb type II QW "W"-active region, as shown in Fig. 2, holds potential for realizing GaAs-based diode lasers with emission wavelengths beyond $\lambda=1.5 \mu \mathrm{m} \mathrm{[32],} \mathrm{[33].} \mathrm{This} \mathrm{approach} \mathrm{utilizes} \mathrm{the} \mathrm{type}$ II band alignment between GaInNAs and GaAsSb. Previously, for GaInAs-GaAsSb type II QW lasers, the PL emission wavelengths were generally limited to $1.2-1.4 \mu \mathrm{m}$, primarily due to the strain relaxation limitation and the relatively large energy bandgap of GaInAs compared with GaInNAs [40]-[42].

The "W" structure design preserves a superior wave function overlap, 2-D density of states [36] and a possible mechanism for Auger recombination suppression [43]. Design studies, using a ten-band $\boldsymbol{k} \cdot \boldsymbol{p}$ simulation, as described in [44], are used to

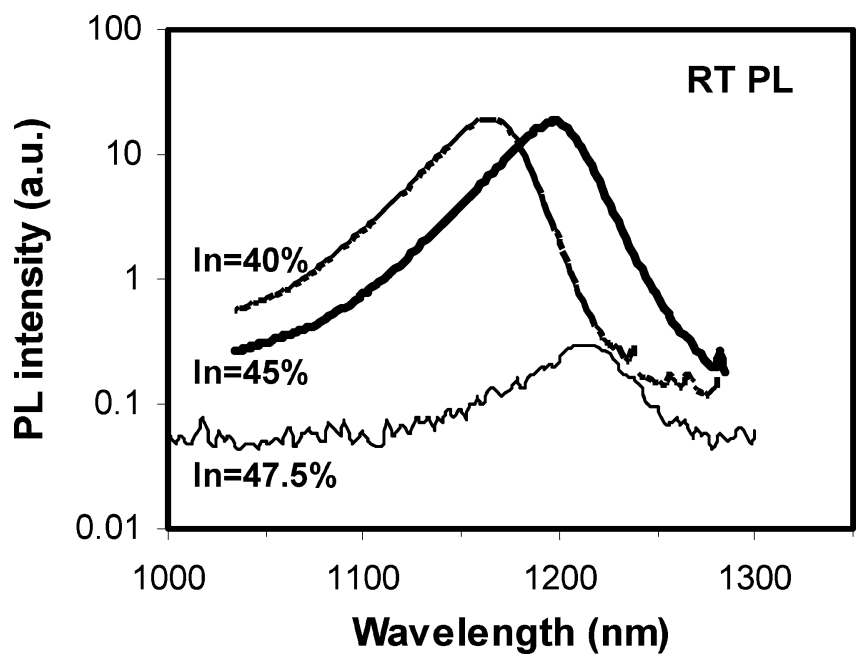

Fig. 4. RT PL spectra of $6.5 \pm 0.5 \mathrm{~nm}$ GaInAs SQW with various In compositions from $40 \%$ to $47.5 \%$. The PL intensity dramatically decreases due to strain relaxation (for In $\sim 47.5 \%$ ).

illustrate the compositional dependence of the optical matrix element and emission wavelength from the type II transition.

First, to clarify the role of N incorporation in the type II QW design, we compare GaInAs/GaAsSb and GaInNAs/GaAsSb type II "W" structures for a fixed structure strain, as shown in Fig. 3. Structure A was selected with $30 \%$ In content, whereas structure B contains $32 \%$ In content and $0.5 \%$ of $\mathrm{N}$ to maintain the same structure strain $(\Delta a / a \sim-2.15 \%)$. The hole well in both structures consists of $\mathrm{GaAs}_{0.7} \mathrm{Sb}_{0.3}$. The emission wavelength is extended from $1246 \mathrm{~nm}$ (structure A) to $1285 \mathrm{~nm}$ (structure B) due to the incorporation of nitrogen into GaInNAs layer and the ability of accommodating a slightly higher In composition. In addition, the electron and hole wave function overlaps were found to be comparable, resulting in optical matrix elements of comparable value, calculated as $5.78 \mathrm{eV} \cdot \AA \AA$ for structure $\mathrm{A}$ and $5.80 \mathrm{eV} \cdot \AA$ for structure B. In addition to wavelength extension, the $\mathrm{N}$-incorporation leads to increased electron confinement, $\Delta E_{c}=135$ and $187 \mathrm{meV}$ for the GaInAs and GaInNAs electron wells, respectively. The increased electron confinement is important for reducing electron leakage in diode lasers, ultimately leading to a reduced temperature sensitivity of the laser threshold current and differential quantum efficiency.

Since both the GaIn(N)As and the GaAsSb layers are compressively strained on GaAs substrates, strain relaxation limits the maximum In and $\mathrm{Sb}$ compositions that are possible. The onset of strain relaxation of $\operatorname{In}_{x} \mathrm{Ga}_{1-x}$ As is known to be growth temperature dependent [45], [46], with lower growth temperatures kinetically limiting the strain relaxation. Experimental studies on single GaInAs QWs help us establish the maximum In content, for a given thickness, prior to strain relaxation. Fig. 4 illustrates the dependence of the room-temperature photoluminescence (RT PL) intensity, for a 6- to 7-nm-wide GaInAs QW, on increasing In content, grown at relatively low growth temperature, $T_{g}=530{ }^{\circ} \mathrm{C}$. From these studies, we find that the maximum In content that can be achieved is approximately $45 \%$ (for an GaInAs well thickness of $6.5 \mathrm{~nm} \pm 0.5 \mathrm{~nm}$ ) before material relaxation due to the large compressive strain 

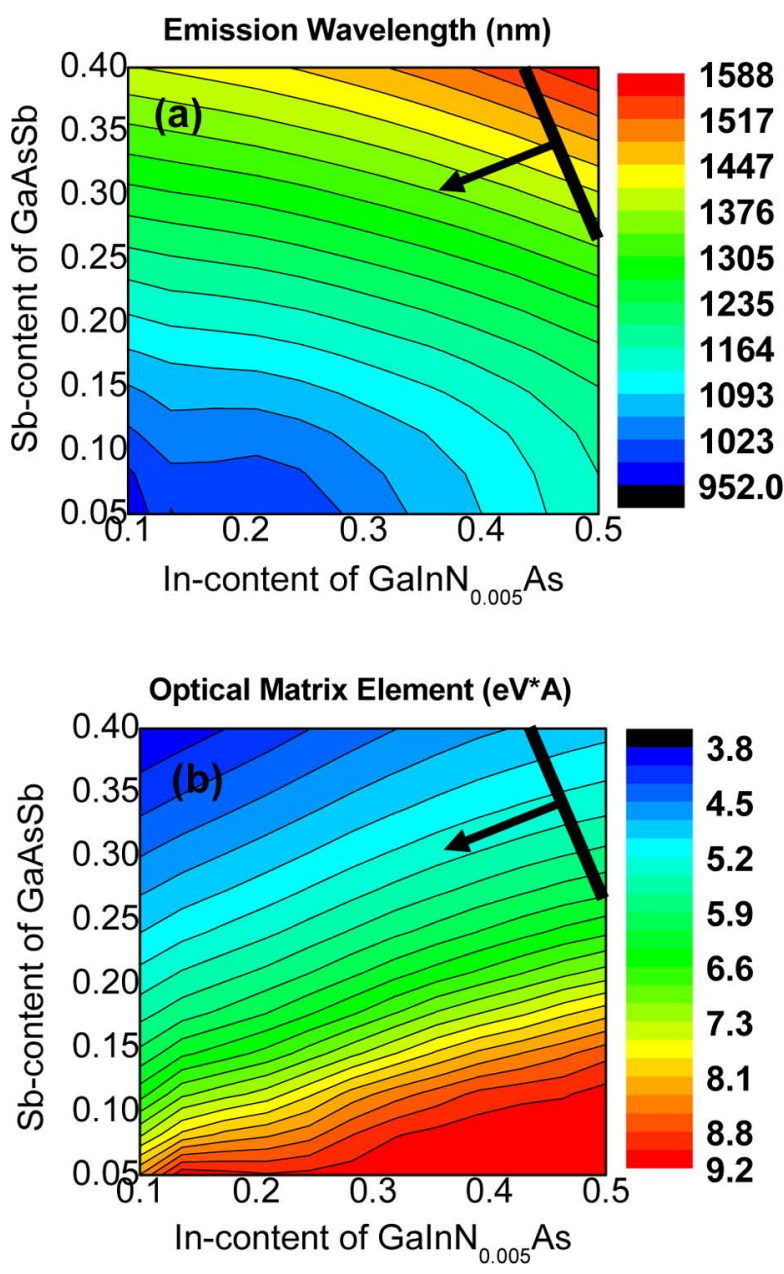

Fig. 5. Contour plots of one period "W" type II QWs. (a) Emission wavelength (nanometers). (b) Optical matrix element (electron volts ·angstrom) at $300 \mathrm{~K}$ by varying In content in GaInNAs and $\mathrm{Sb}$ content in GaAsSb layers, with $2.5 \mathrm{~nm}$ GaInNAs $(N=0.5 \%) / 2.5 \mathrm{~nm} \mathrm{GaAsSb}$ for the laser active region. The regions indicated by the arrows fall within the expected material strain limitation.

$(\Delta a / a \sim 2.7 \%)$, resulting in degradation of the photoluminescence (PL) intensity.

Contour plots, shown in Fig. 5, help to understand the design space and tradeoff issues of the type II QW. The $\mathrm{N}$ content is chosen to be minimal $(N \sim 0.5 \%)$, similar to that utilized for high-performance 1.3- $\mu$ m-emitting type I GaInNAs QW lasers [19]. The GaInNAs and GaAsSb layer thicknesses are both fixed at $2.5 \mathrm{~nm}$, since thin layers are essential for achieving significant wave function spatial overlap. We see that increasing the In content and $\mathrm{Sb}$ content both result in an extension in emission wavelength due to a reduced bandgap for the corresponding layers. However, increasing the Sb content results in a lower matrix element (i.e., lower electron-hole wave function overlap) while increasing In content leads to a higher matrix element. A higher Sb content leads to tight hole wave function confinement, and hence, reduced spatial overlap with the electron wave function. Furthermore, considering the maximum average strain that can be experimentally achieved in a 7-nm-wide $\mathrm{In}_{x} \mathrm{Ga}_{1-x}$ As SQW, $\Delta a / a \sim 2.7 \%$ (e.g., $x \sim 0.45$ In content), a similar strain constraint is expected for the "W" structures. This strain constraint limits the design space, as indicated by

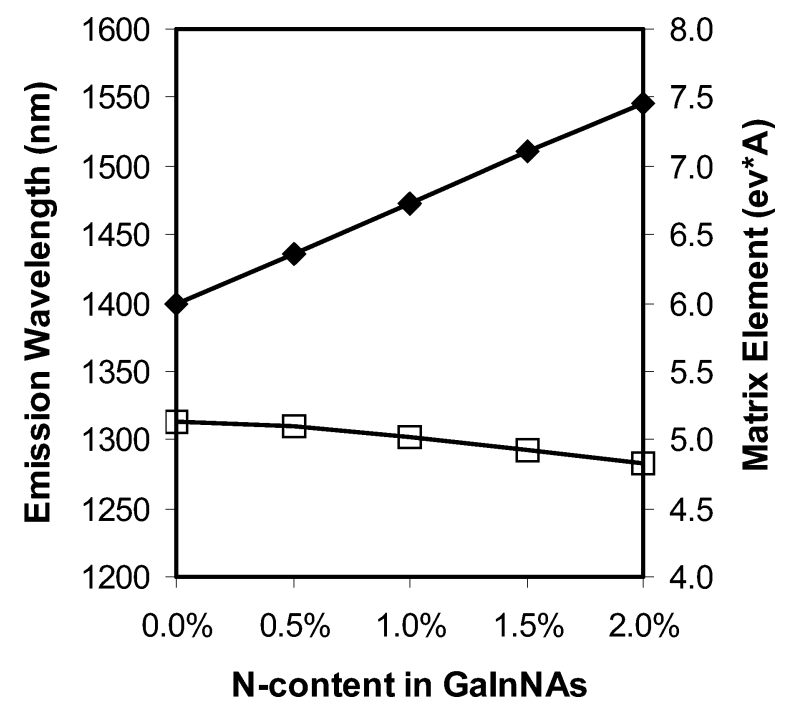

Fig. 6. Calculated emission wavelength (solid diamond) and optical matrix element (open square) at $300 \mathrm{~K}$ of a $\mathrm{Ga}_{0.6} \operatorname{In}_{0.4} \mathrm{~N}_{x} \mathrm{As}_{1-x} / \mathrm{GaAs}_{0.65} \mathrm{Sb}_{0.35}$ "W" type II QW with varying N content. Both the GaInNAs and GaAsSb layers were fixed at $2.5 \mathrm{~nm}$

the solid line and arrow in Fig. 5. Thus, by choosing the highest possible In content, given the strain limitation, long-wavelength emission from the type II "W" QW with good optical transition strength can be achieved. The ability to accommodate higher average strain may be possible by employing a lower growth temperature $\left(T_{g}<500{ }^{\circ} \mathrm{C}\right)$, and precursor sources such as tertiarybutylarsine (TBA) and ethyl-based sources that decompose efficiently at low growth temperatures. However, as the design target wavelength is increased, as shown in Fig. 5, a larger number of $\mathrm{W}$-stages will be necessary to achieve sufficient optical gain due to the reduction in wave function overlap. Optical gain simulations [33] indicate that a single stage of $\mathrm{W}$ structure should be sufficient for achieving lasing operation in 1.5- $\mu \mathrm{m}$-emitting diode lasers, with a radiative component of the threshold current density ( $\left.J_{\mathrm{th} \_ \text {Rad }}\right)$ of $150-250 \mathrm{~A} / \mathrm{cm}^{2}$ for the typical threshold gain requirements $\left(g_{\mathrm{th}} \sim 1000-2000 \mathrm{~cm}^{-1}\right)$. However, nonradiative recombination, which is known to play a significant role in dilute nitride materials, ultimately determines the number of stages required to provide sufficient optical gain. In fact, the experimental results presented here on two- to threestage active layer diode lasers indicate that an even larger number of stages is required to provide sufficient gain for RT lasing.

An increased incorporation of $\mathrm{N}$ also leads to longer emission wavelength. For example, by varying the $\mathrm{N}$ content from $0 \%$ to $2 \%$, the emission wavelength can be extended from 1.4 to $1.55 \mu \mathrm{m}$ with only a small reduction of optical matrix element (for fixed In content of $40 \%$ and Sb content of 35\%), as shown in Fig. 6. However, it is desirable to minimize the amount of nitrogen incorporation due to the decrease of minority carrier life time with increased $\mathrm{N}$ content [47].

\section{EXPERIMENT}

The dilute nitride type II QW structures reported here were grown by MOCVD at an active region growth temperature of 
$530{ }^{\circ} \mathrm{C}$ and reactor pressure of 100 mbar, growth conditions similar to those utilized for high-performance 1.3 - $\mu$ m-emitting GaInNAs type I QW lasers [19]. Trimethylgallium (TMGa), trimethylaluminium (TMAl), and trimethylindium (TMIn) are used as group III sources and $\mathrm{AsH}_{3}, \mathrm{PH}_{3}$, and U-DMHy are used as group $\mathrm{V}$ sources. The dopant sources are $\mathrm{SiH}_{4}$ and diethylzinc (DEZn) for the $n$ - and p-dopants, respectively. The gas-switching scheme was studied previously and utilized here for achieving good GaAsSb interfaces [48]. A GaAs SCH and active region, similar to that depicted in the schematic band diagram of Fig. 1, are grown undoped. The n-cladding and pcladding layers consist of $\mathrm{Al}_{0.74} \mathrm{Ga}_{0.26}$ As, grown at $775^{\circ} \mathrm{C}$ and 640-700 ${ }^{\circ} \mathrm{C}$, respectively. Both cladding layers are designed with doping levels of approximately $1 \times 10^{18} \mathrm{~cm}^{-3}$. The tensile-strained buffer layer consists of a $3 \mathrm{~nm} \mathrm{GaAs}{ }_{0.67} \mathrm{P}_{0.33}$, which we found to be crucial for the growth of the highly strained GaIn(N)As QW material system on top of a high Al content lower cladding layer [19].

The structural and optical characteristics of the GaInNAs/GaAsSb type II QW structures have been previously reported [49], [50], demonstrating RT PL emission wavelengths $>1.5 \mu \mathrm{m}$ for structures utilizing relatively high $\mathrm{N}$ content $(N \sim 2 \%)$, which is in good agreement with theoretical results. These previous studies demonstrated improved PL intensity as well as an emission wavelength blue-shift with thermal annealing, similar to that observed with type I GaInNAs QWs. Thermal annealing is known to improve the material quality of type I GaInNAs QW at the expense of wavelength blue-shift [51]-[54]. The influence of annealing on emission wavelength has been attributed to: 1) changes of bonding configuration of the nitrogen atom nearest neighbor [55], [56]; 2) gallium, indium, and nitrogen atoms interdiffusion [57]-[59]; and 3) QW profile modification from atomic diffusion at the well/barrier interface [55]. In the type II GaInNAs/GaAsSb $\mathrm{W}$-structures, we expect that the impact of thermal annealing on the atomic diffusion at the well/barrier interfaces may be more severe, compared with GaInNAs/GaAs type I QWs, due to the significant change in group $\mathrm{V}$ species across the interface. Also note that this thermal-annealing-induced emission blue-shift presents an additional uncertainty when comparing experiment to the simulated transitions.

To evaluate the electroluminescence (EL) behavior of the type II active regions, diode laser structures were grown and fabricated into broad area edge-emitting devices. The lasing characteristics are measured under pulsed condition with pulsewidth of $5 \mu$ s and duty cycle of $1 \%$. Devices were mounted inside a cryostat, to allow for temperature-dependent EL and PL spectral measurements. The PL was measured with excitation by an argon ion laser $(\lambda \sim 514.5 \mathrm{~nm})$ and detection by a liquidnitrogen-cooled Ge photodiode. The EL measurements are performed on as-cleaved broad area laser devices, with an oxidedefined stripe width of $30 \mu \mathrm{m}$. The metal contacts consist of 25 $\mathrm{nm} \mathrm{Ti} / 50 \mathrm{~nm} \mathrm{Pt} / 150 \mathrm{~nm}$ Au and $20 \mathrm{~nm} \mathrm{Ge} / 100 \mathrm{~nm} \mathrm{GeAu} / 50 \mathrm{~nm}$ $\mathrm{Ni} / 300 \mathrm{~nm} \mathrm{Au}$ for $\mathrm{p}$-contact and n-contact, respectively. The contact annealing of the devices is accomplished under forming gas $\left(10 \% \mathrm{H}_{2}+90 \% \mathrm{~N}_{2}\right)$ at a temperature of $370{ }^{\circ} \mathrm{C}$ for duration of $30 \mathrm{~s}$.

\section{GaInNAs/GaAsSb Type II QW: MATERIAL AND DEVICE CHARACTERISTICS}

The simulated energy band diagrams, measured highresolution X-ray diffraction (HRXRD) spectrum, PL, and EL spectra of a two-stage "W" QW laser structure are shown in Fig. 7. Calibration of the $\mathrm{W}$-active region consists of growing $\mathrm{In}_{0.4} \mathrm{Ga}_{0.6} \mathrm{As}_{1-y} \mathrm{~N}_{y} / \mathrm{GaAs}$ and $\mathrm{GaAs}_{1-y} \mathrm{Sb}_{y} / \mathrm{GaAs}$ superlattice (SL) structures for HRXRD analysis in order to determine the $\mathrm{N}$ and $\mathrm{Sb}$ contents. Subsequently, from the HRXRD dynamical simulation of the two-stage laser structure [Fig. 7(a)], the QW active region was determined to consist of an $\mathrm{In}_{0.4} \mathrm{Ga}_{0.6} \mathrm{As}_{0.995} \mathrm{~N}_{0.005}(2.5 \mathrm{~nm}) / \mathrm{GaAs}_{0.68} \mathrm{Sb}_{0.32}(22.3 \mathrm{~nm})$ W-structure with GaAs $(8.5 \mathrm{~nm})$ and $\mathrm{GaAs}_{0.9} \mathrm{P}_{0.1}(4.5 \mathrm{~nm})$ barriers. The p-type $\mathrm{Al}_{0.74} \mathrm{Ga}_{0.26}$ As cladding layer of the laser structure was grown at $640{ }^{\circ} \mathrm{C}$, which thermally anneals the dilute nitride active region. Based on this structure, we can compare the experimental and simulated optical transitions using a ten-band $\boldsymbol{k}$. $\boldsymbol{p}$ model [Fig. 7(b)]. Fig. 7(c) shows the PL spectra with different laser pump power. With the lower pump power density $\left(\sim 50 \mathrm{~mW} / \mathrm{cm}^{2}\right)$, the PL spectrum shows a primary peak with a shorter wavelength shoulder. With the higher power density $\left(\sim 100 \mathrm{~mW} / \mathrm{cm}^{2}\right)$, the PL spectrum contains a primary peak at shorter wavelength with a longer wavelength shoulder, due to carrier band-filling. At low pump power densities, the long-wavelength peak in the emission $(1278 \mathrm{~nm})$ is believed to originate from transitions from the lowest electron state (C1 S) to the lowest heavy-hole state (HH1). The simulated $\mathrm{C} 1 \mathrm{~S}-\mathrm{HH} 1$ transition wavelength is $1278.4 \mathrm{~nm}$ based on the structure, as determined from XRD measurements. The higher energy peak $(1120 \mathrm{~nm})$ in the emission spectrum is difficult to identify with confidence, although it may correspond to $\mathrm{C} 1 \mathrm{~S}-\mathrm{LH} 1$ transition, with a simulated emission wavelength of $\sim 1099 \mathrm{~nm}$. With increasing laser pump power [Fig. 7(d)], we observe from the PL spectra that the emission wavelength blue-shifts from 1278 to $1232 \mathrm{~nm}$, corresponding to a change in the transition energy of $\Delta E \sim 30 \mathrm{meV}$, consistent with a type II transition [42], [60]-[62]. Previous reports on GaInAs/GaAsSb type II QWs report PL $\Delta E$ shifts of $\sim 22.4 \mathrm{meV}$ for increasing laser pump power [62]. Compared with type I QWs, the emission wavelength blue-shift observed here for the type II QW is significantly more severe. For example, the PL emission blue-shifts were found to be $\sim 13$ and $\sim 4 \mathrm{meV}$ for type II (GaAsSb/GaAs) and type I (GaAsSb/GaAlAs), respectively, with increased laser pump power [63]. The emission blue-shift observed in type II QWs has been attributed to energy band-bending associated with charge separation in the type II heterostructure, which increases with increasing carrier density [60]-[62].

Fig. 7(e) shows the measured EL spectra at $T=14 \mathrm{~K}$ from the same two-stage W-structure QW laser, with a stripe width of $30 \mu \mathrm{m}$ and $3 \mathrm{~mm}$ cavity length. With increasing current injection, we find behavior similar to that observed for optical injection, the emission wavelength of the CS1-HH1 transition blue-shifts from $1200 \mathrm{~nm}$ (400 mA) to $1173 \mathrm{~nm}(1890 \mathrm{~mA})$, whereas the higher energy transition (shorter wavelength) emission wavelength blue-shifts from 1130 to $1110 \mathrm{~nm}$. At laser threshold (2000 mA, $J_{\mathrm{th}} \sim 2.2 \mathrm{kA} / \mathrm{cm}^{2}$ ) that occurs at high 


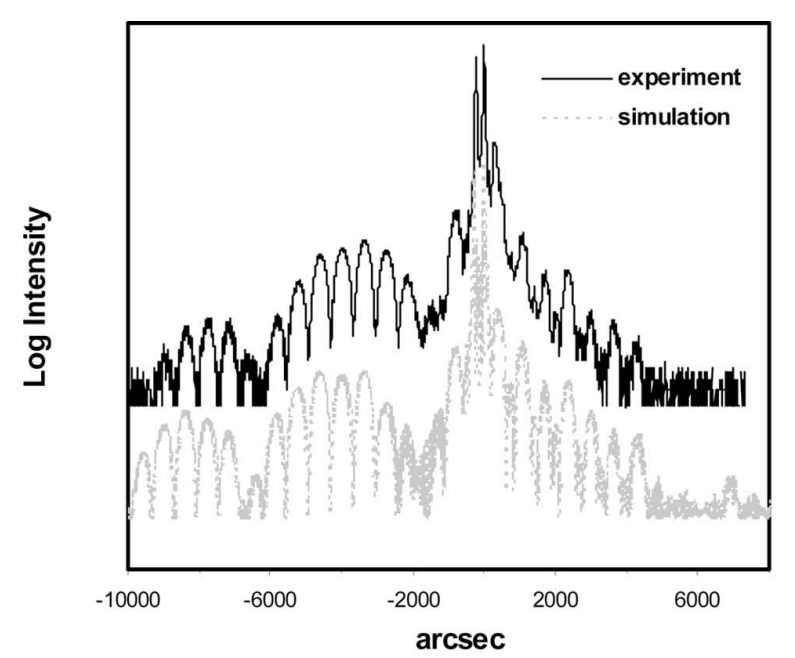

(a)

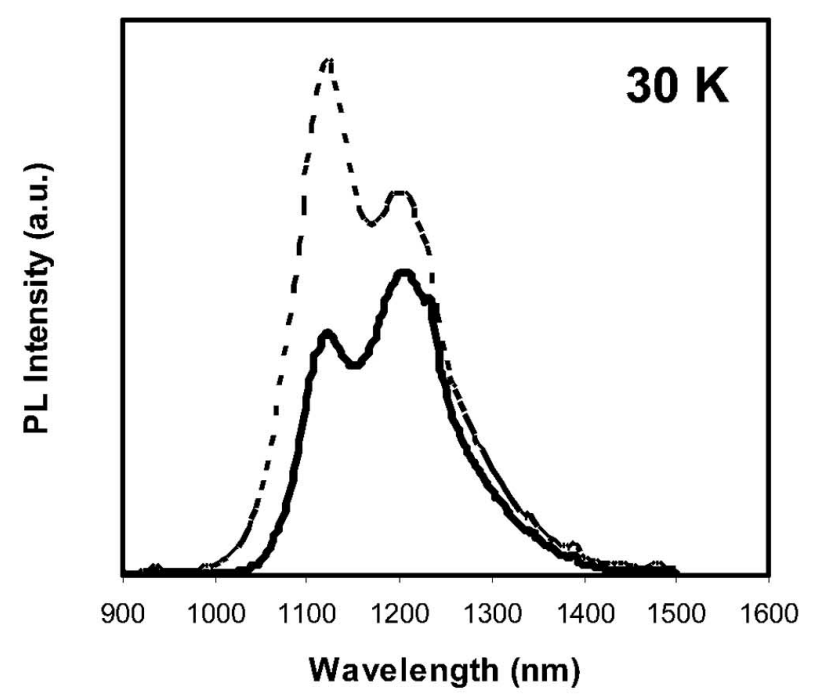

(c)

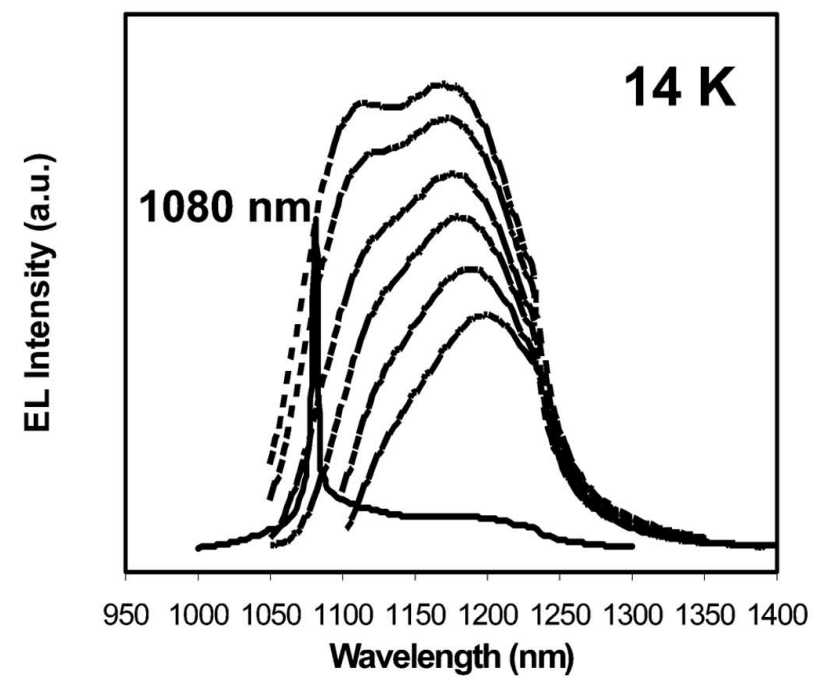

(e)

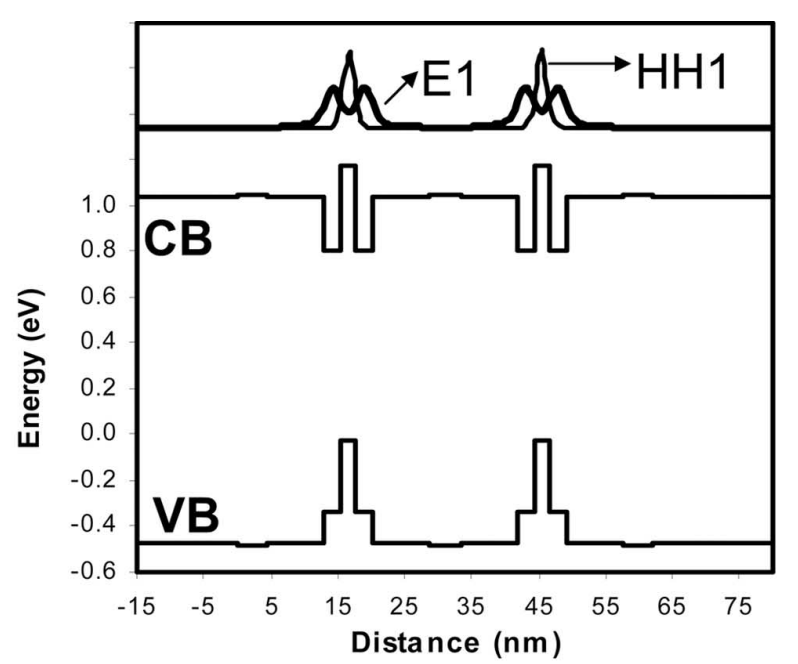

(b)

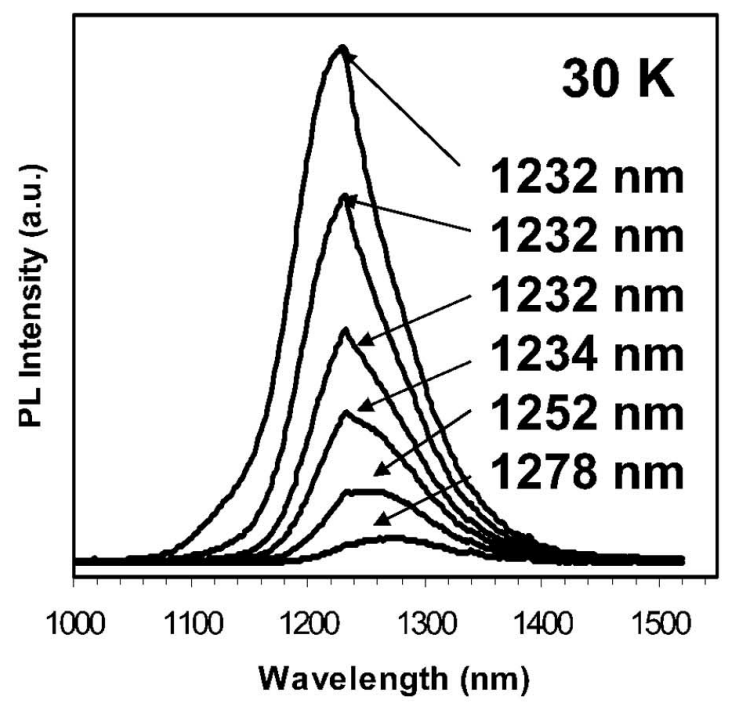

(d)

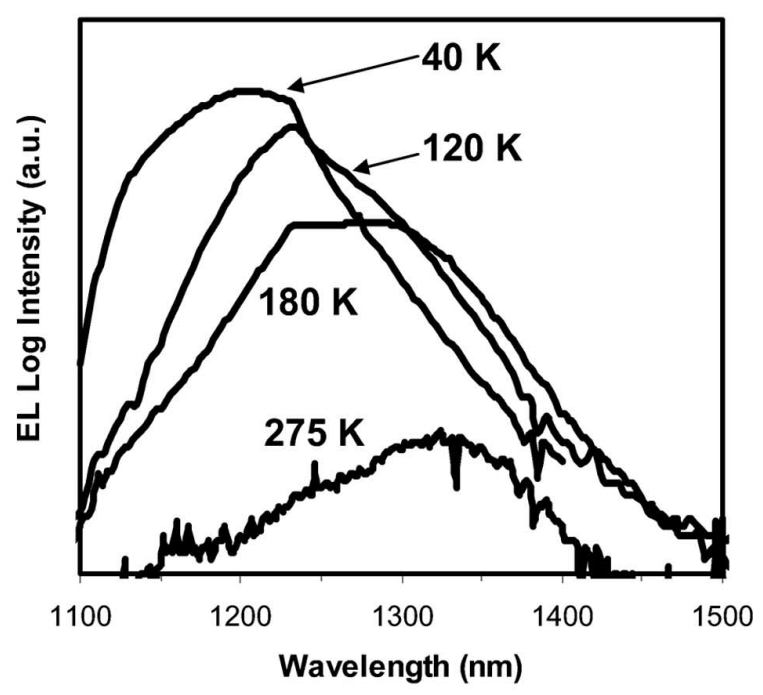

(f)

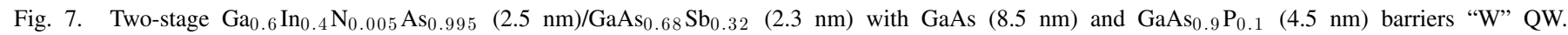

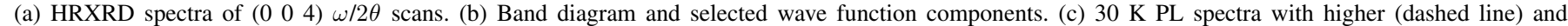

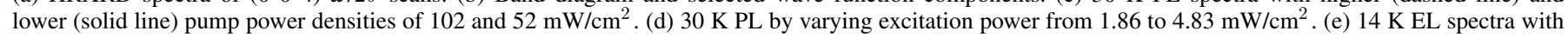
various pump currents (400-1890 mA). (f) Temperature-dependent PL from $39 \mathrm{~K}$ to $275 \mathrm{~K}$ at a fixed excitation current of $265 \mathrm{~mA}$. 
carrier injection, the carrier density clamps and the wavelength is fixed at $1080 \mathrm{~nm}$. The temperature-dependent EL spectra measured under low current injection $(265 \mathrm{~mA})$ conditions is shown in Fig. 7(f). With increasing thermal excitation, the emission red-shifts from $1208 \mathrm{~nm}$ (at $39 \mathrm{~K}$ ) to $1235 \mathrm{~nm}$ (at $120 \mathrm{~K}$ ), where the higher energy type II transition dominates. For $T>180 \mathrm{~K}$, the relative intensity of the dominating CS1-HH1 type II transition dominates and decreases with increasing temperature. The EL spectral peak occurs near $1325 \mathrm{~nm}$ at $T=275 \mathrm{~K}$.

Laser structures employing higher $\mathrm{N}$ content GaInNAs electron wells with an In content of $37 \%$ and a gas phase N/V ratio in the 0.994-0.996 range, corresponding to $\mathrm{N}$ contents estimated to be in the range of $1.5-2 \%$, were also grown and characterized. The $\mathrm{Sb}$ content of the $\mathrm{GaAs}_{1-y} \mathrm{Sb}_{y}$ is estimated from XRD calibration samples to be $y \sim 0.25$. Fig. 8(a)-(c) shows the PL and EL spectra of a three-stage $\mathrm{In}_{0.37} \mathrm{Ga}_{0.62} \mathrm{As}_{0.98} \mathrm{~N}_{0.02}-\mathrm{GaAs}_{0.75} \mathrm{Sb}_{0.25}$ "W" $\mathrm{QW}$ laser, respectively. The PL spectrum exhibits a peak wavelength at 1300 $\mathrm{nm}$ at $30 \mathrm{~K}$ [Fig. 8(b)], is blue-shifted from the as-grown PL at $\sim 1425 \mathrm{~nm}$ [Fig. 8(a)], due to a high-temperature $\left(720{ }^{\circ} \mathrm{C}\right.$, $25 \mathrm{~min}$ ) anneal during the growth of the p:AlGaAs cladding layer. Lower temperature cladding layer growth can be used to minimize this blue-shift. Similar to that observed for the lower $\mathrm{N}$ content $(\mathrm{N} \sim 0.5 \%) \mathrm{W}$-structure lasers discussed above, the peak wavelength of the EL spectrum [Fig. 8(c)] blue-shifts under increasing injection current up to the lasing wavelength of $1176 \mathrm{~nm}$ when the threshold condition is reached and carrier density is clamped. The threshold current density is relatively high, corresponding to $J_{\mathrm{th}} \sim 2 \mathrm{kA} / \mathrm{cm}^{2}$. A gradually shortened emission wavelength was observed with increasing injection current, indicating that the emission blue-shift depends strongly on the carrier density. Lasing appears to occur on the higher energy transition of the $\mathrm{W}$-structure, presumably due to excessive carrier band-filling at high injection currents. From these device results, it is evident that an insufficient gain is provided from the lowest energy type II transition (C1 S-HH1) to reach the laser threshold. This behavior is similar to what occurs in selfassembled QD lasers with high cavity losses, where lasing generally occurs on excited QD states due to the insufficient ground state gain [64]. In QD lasers, multistack active regions have been successful in increasing the ground state optical gain. Thus, in order to avoid the excessive band-filling and provide sufficient gain in the type II QW active devices to achieve ground-state lasing, higher gain per stage (i.e., increased wave function overlap and reduced nonradiative recombination) and/or an increased number of active stages must be employed.

\section{StRAin Compensated Type II GaNAs/GaAsSb QWs ON GaAs SubSTRATES}

One of the primary drawbacks of the GaInNAs/GaAsSb type II QW design, as discussed in Sections II-IV is that both the electron well and the hole well are under high compressive strain, which ultimately limits extending the active volume and emission wavelength of this design. As a result, GaAsP barriers are required between the GaInNAs/GaAsSb W-stages to allow for multistage structures, with a potential for achieving

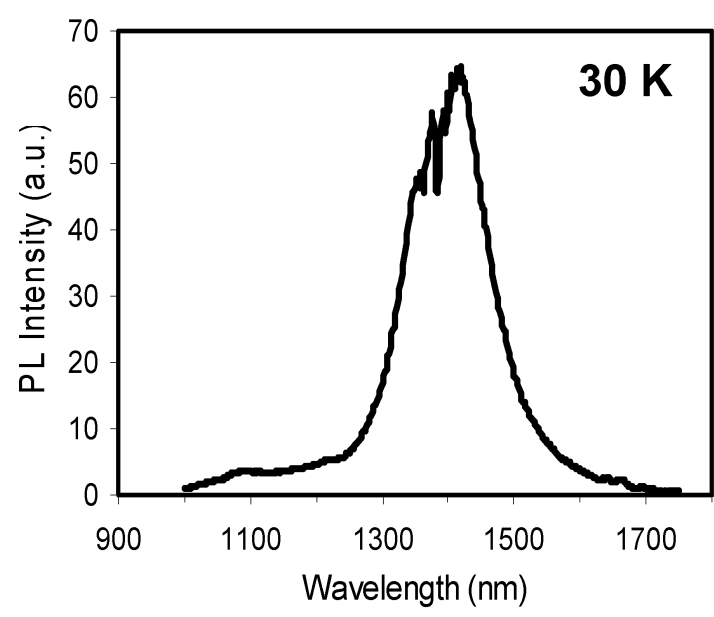

(a)

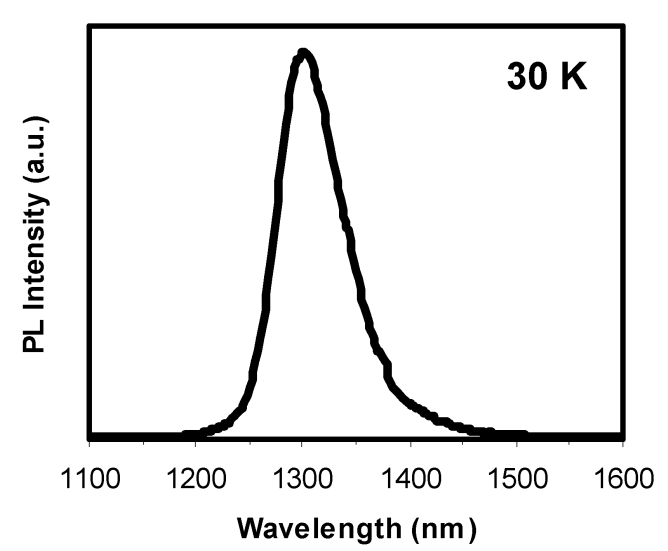

(b)



(c)

Fig. 8. (a) $30 \mathrm{~K} \mathrm{PL}$ as-grown. (b) $30 \mathrm{~K} \mathrm{PL}$ annealed under $720{ }^{\circ} \mathrm{C}, 25$ min. (c) $T=150 \mathrm{~K}$ EL spectra under pulsed operation of the three-stage $\mathrm{Ga}_{0.62} \mathrm{In}_{0.37} \mathrm{~N}_{0.02} \mathrm{As}_{0.98}-\mathrm{GaAs}_{0.7} \mathrm{Sb}_{0.3}$ "W" QW laser $(W=30 \mu \mathrm{m}, L=$ $3 \mathrm{~mm}$ ). The EL spectra were taken under increasing injection level from 200 $\mathrm{mA}$ to $1.8 \mathrm{~A}$.

high ground-state optical gain with minimized carrier bandfilling. An alternate, strain-compensated, dilute nitride structure (Fig. 9), was proposed in [32], [33], and [65], consisting of a GaNAs/GaAsSb/GaNAs W-structure.The electrons are confined in the GaNAs electron QWs, sandwiched with large $\Delta E_{c}$ of GaAs and GaAsSb. The holes in GaAsSb hole QWs, are 


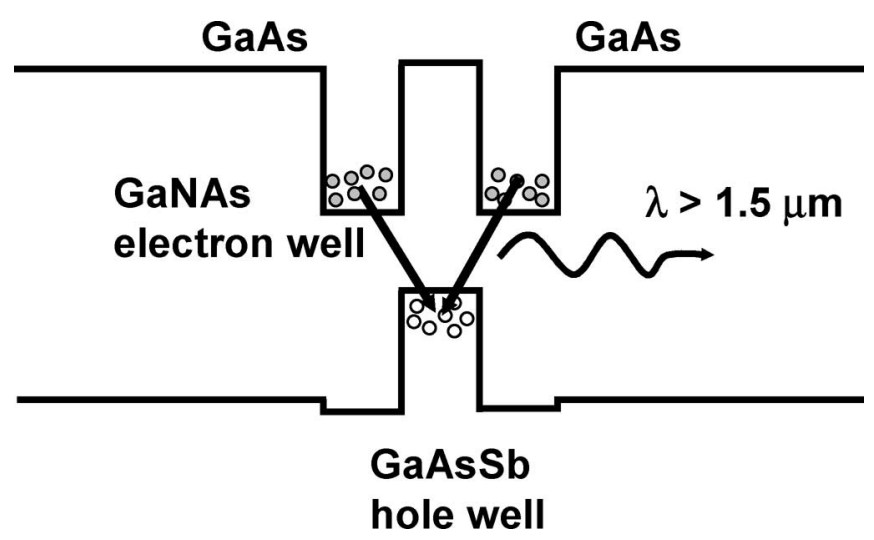

Fig. 9. Schematic energy band diagram of GaNAs/GaAsSb type II W structure.

confined by the large $\Delta E_{v}$ of GaAsSb and GaNAs. A comprehensive design analysis of this structure was presented in [32] and [33], indicating the feasibility of employing such an active region for diode laser emission at $1.55 \mu \mathrm{m}$. These design studies indicate that optical gain values comparable to that of the GaInNAs/GaAsSb W-structure can be achieved, although higher $\mathrm{N}$ content is required for a given emission wavelength.

We previously reported [66] on the structural and optical properties of four-period $(5.7 \mathrm{~nm}) \mathrm{GaAs}_{0.978} \mathrm{~N}_{0.022} /(4.3 \mathrm{~nm})$ $\mathrm{GaAs}_{0.78} \mathrm{Sb}_{0.22} \mathrm{SL}$ structures grown by MOCVD. RT PL emission at $\lambda=1425 \mathrm{~nm}$ was observed, after optimization of the postgrowth thermal annealing. However, because of the relatively thick layers employed in [66], the electron-hole wave function overlap will be poor for these SL structures, and thus, would not be suitable for a diode laser active region. Furthermore, to maintain the two-dimensional density of states, a $\mathrm{W}$-structure is advantageous over a SL structure [36]. Employing thinner electron and hole layers within the $\mathrm{W}$ structure necessitates a larger $\mathrm{N}$ content to offset the increased quantum size effects, if longwavelength emission is to be achieved. Four-period $(2.30 \mathrm{~nm})$ $\mathrm{GaAs}_{0.97} \mathrm{~N}_{0.03} /(1.82 \mathrm{~nm}) \mathrm{GaAs}_{0.715} \mathrm{Sb}_{0.285} \mathrm{SL}$ structures have been grown and characterized by HRXRD, TEM, and PL analysis, as shown in Fig. 10. As in the case of the GaInNAs/GaAsSb type II QW structure, we find thermal annealing significantly improves the PL intensity with a corresponding emission blueshift [Fig. 10(c) and (d)]. The simulated CS1-HH1 transition at $30 \mathrm{~K}$ is $918 \mathrm{meV}(1351 \mathrm{~nm})$, in reasonable agreement with the experimental results.

Structures with increased N content in the GaNAs electron wells exhibit longer emission wavelength, as expected. W-structures similar to that of Fig. 11, except utilizing higher $\mathrm{N}$ content, $\mathrm{GaAs}_{0.96} \mathrm{~N}_{0.04}$ electron wells exhibit RT PL emission at $1.54 \mu \mathrm{m}$, in good agreement with the simulated $\mathrm{C} 1$ S-HH1 transition $(1.5 \mu \mathrm{m})$. Higher temperature thermal annealing improves PL intensity, but at the expense of an emission wavelength blue-shift. Because of the strain compensation in these GaNAs/GaAsSb QW structures, we expect that many Wstages can be grown without strain relaxation, ideal for achieving high optical gain. Thus, these strain compensated active regions appear promising for implementation into diode laser structures.

\section{LASER StRUCTURE OPTIMIZATION AND WAVELENGTH EXTENSION}

Structure optimization considerations include: 1) increased wave function overlap by employing ultrathin layers. However, this leads to increased quantum size effects and an undesirable emission wavelength blue-shift; 2) larger number of "W"-stages to increase the active volume and reduce the threshold carrier density per stage; 3) increased Sb content in the hole well, improving the hole confinement and extending emission wavelength at the expense of wave function overlap; and 4) reduced nonradiative recombination, possibly achieved through optimization of the annealing conditions of the dilute nitride materials.

The impact of Sb content on the hole confinement is illustrated in Fig. 12, where the simulated energy band structure is shown for active regions with different $\mathrm{Sb}$ content $\mathrm{GaAs}_{1-x} \mathrm{Sb}_{x}$ hole wells ( $x=0.1, x=0.2, x=0.3$ ). We see that, to provide a relatively large $\Delta E_{v}>164 \mathrm{meV}$, it is necessary to utilize an Sb content $x>0.2$. In addition to providing sufficient hole confinement, to achieve long-wavelength emission, a high $\mathrm{Sb}$ content is desired in the thin GaAsSb alloy layers. However, $\mathrm{Sb}$ incorporation efficiencies are limited for the growth of thin, pseudomorphically strained GaAsSb layers on GaAs, due to "lattice latching" effects [67]. Along with the strain-induced effects, GaAsSb growth is complicated by the segregation of $\mathrm{Sb}$ atoms on the growth surface [68]. Low growth temperatures and low V/III ratios are used to increase Sb incorporation in GaAsSb films. The kinetic effects during the MOVPE are pronounced at lower growth temperatures $\left(\sim 500{ }^{\circ} \mathrm{C}\right)$ due to incomplete thermal decomposition of commonly used methyl and hydride precursors. We have performed a study [69] conducted to determine the effect of $\mathrm{Ga}$ and $\mathrm{Sb}$ precursor chemistry on $\mathrm{Sb}$ incorporation efficiencies in relaxed and strained $\mathrm{GaAsSb}$ films on GaAs substrates. Ethyl precursors with relatively low decomposition temperatures produce elemental species on the growth surface and result into higher $\mathrm{Sb}$ incorporation. We have reported strained $\mathrm{GaAs}_{1-x} \mathrm{Sb}_{x} / \mathrm{GaAs}$ QWs with $x \sim 0.48$ using such techniques [68]. Such changes in the growth chemistry would allow higher $\mathrm{Sb}$ content layers, and hence, an extended range of wavelength and control in type II structures.

With smaller threshold carrier density, achievable using a larger number (eight to ten) of strain compensated active layer stages, we expect that the effects of charge separation and band-filling can be significantly reduced, allowing lasing in the $1.5 \mu \mathrm{m}$ range from optimized thickness devices. The challenges are to strain-compensate between each $\mathrm{W}$-stage, so as to decouple the interstage strain and allow for a larger active volume. Recent experimental studies on type II GaInAs/GaAsSb "W" laser structures on GaAs substrate also found optical gain was significantly lower than expected from theory and indicate that the optimization of QW thickness and an increased number of "W"-stages are required to improve the optical gain and to reduce the threshold carrier density [70]. Furthermore, in GaSb-based type II mid-IR lasers, multistage active regions (five to eight stages), have been successful at minimizing emission wavelength blue-shifts, allowing for low threshold current density long-wavelength emission [37]. 



Fig. 10. (a) HRXRD spectra of $\left(\begin{array}{lll}0 & 0 & 4\end{array}\right) \omega / 2 \theta$ scans of four periods GaNAs/GaAsSb SL. (b) Cross-sectional transmission electron microscopy image. (c) 30 K $\mathrm{PL}$ spectra of as-grown and after $640{ }^{\circ} \mathrm{C}$ annealing of the single-stage GaNAs/GaAsSb "W" QW. (d) $300 \mathrm{PL}$ spectrum after $640{ }^{\circ} \mathrm{C}$ annealing of the single-stage GaNAs/GaAsSb "W" QW.

Due to strain limitations, and the necessity to minimize the $\mathrm{N}$ content for high optical quality, extension to wavelengths beyond $1.5 \mu \mathrm{m}$ using a dilute nitride type II QW active region will require the use of an InP substrate. Mid-IR $(2-5 \mu \mathrm{m})$ sources produced on conventional InP substrates could have significant advantages over existing type I and type II QW lasers that utilize $\mathrm{GaSb}$ or InAs substrates. GaSb-based type I GaInAsSb/ $\mathrm{AlGaAsSb}$ lasers have realized $\mathrm{CW}$ operation at room temperature with wavelengths as long as $\sim 2.96 \mu \mathrm{m}$, although they suffer from weak hole confinement at the longer wavelengths [71], [72]. A further improvement of the valence-band offset can be achieved by the introduction of an AlGaInAsSb quinternary barrier [73]. Even though good performance has been achieved, immature GaSb-based growth and processing technology have hindered the progress of this technology.

InP offers many advantages over GaSb such as better thermal conductivity, the ability to utilize a buried heterostructure, or buried grating distributed feedback design, incorporation into a VCSEL design, and optical pumping capability with highefficiency near-IR diode lasers (i.e., $\lambda=980 \mathrm{~nm}$ ).

The conventional approach of extending the emission wavelength on an InP substrate, i.e., highly strained GaInAs-active regions, encounter difficulties for wavelengths $>2 \mu \mathrm{m}$ [74]. GaInAs/GaAsSb type II "W" QW structures on InP substrate have also been realized by Peter et al., employing a SL active region consisting of compressively strained GaInAs and tensile-strained GaAsSb [75]. The CW room-temperature laser emission wavelength of these GaInAs/GaAsSb type II devices has been limited to about $1.7 \mu \mathrm{m}$, due to the maximum lattice strain that the structures can accommodate and the relatively large energy bandgap of the GaInAs employed.

Previously, we reported a design study of a dilute nitride In(Ga)AsN/GaAsSb type II QW structure on an InP substrate for achieving 2 5 $\mu \mathrm{m}$ emission [34]. Although the growth of these materials are quite challenging because of the inhibition of $\mathrm{N}$ incorporation into high In content GaInAs alloys when using 


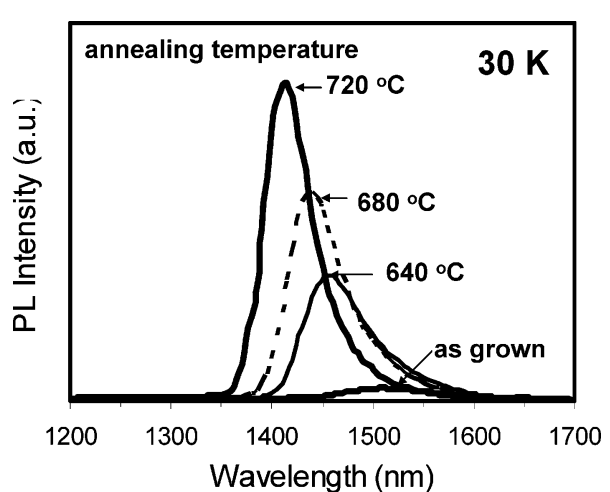

(a)

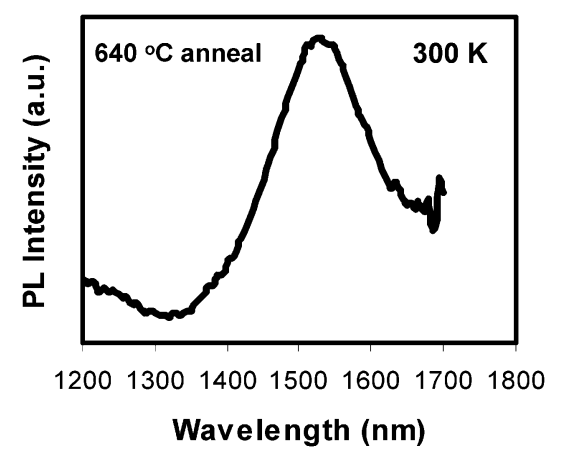

(b)

Fig. 11. PL spectra of GaNAs/GaAsSb type II QWs. (a) 30 K PL of asgrown sample and with the annealing temperatures of 640,680 , and $720^{\circ} \mathrm{C}$. (b) $300 \mathrm{~K} \mathrm{PL}$ spectrum after $640{ }^{\circ} \mathrm{C}$ annealing.

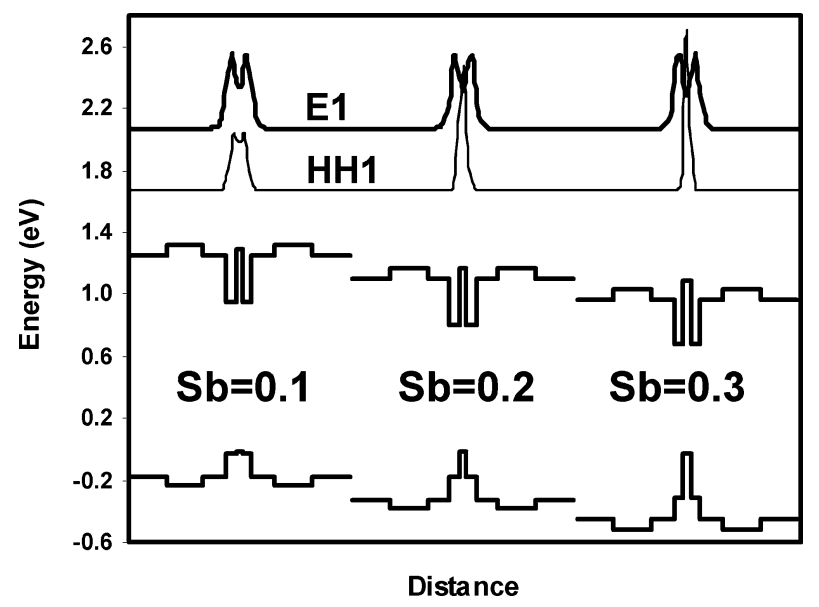

Fig. 12. Simulated energy band diagrams and selected wave function components of $x=0.1,0.2$, and 0.3 in $\mathrm{GaIn}_{0.37} \mathrm{~N}_{0.02} \mathrm{As}_{\mathrm{GaAs}} \mathrm{Ga}_{1-x} \mathrm{Sb}_{x}$ of $2.5 \mathrm{~nm}$ in each QW layer and with $6 \mathrm{~nm} \mathrm{GaAs}{ }_{0.85} \mathrm{P}_{0.15}$ barriers surrounded.

MOCVD growth [49]. An alternate type II QW design consisting of GaAsSbN/GaAsSb on InP was proposed [35], eliminating the need for incorporation of nitrogen into high In content GaInAs. The use of GaAsSbN electron wells should allow for increased $\mathrm{N}$-incorporation over previous designs [34] due to the elimination of indium in the material. While the growth of GaAsSbN compounds have been reported previously on GaAs substrates [76], little is known concerning the growth and properties of strained GaAsSbN QWs on InP. A design analysis of a strain-compensated structure (tensile-strained GaAsSbN electron wells and a compressively strained GaAsSb hole well) indicates that emission is possible in the $2-3.5 \mu \mathrm{m}$ wavelength range [35]. Preliminary experimental studies on the growth of strained GaAsSb/InP and the incorporation of $\mathrm{N}$ into GaAsSb QWs on InP was presented in [77]-[79]. A significant improvement in the optical quality of the strained $\mathrm{GaAs}_{1-y-z} \mathrm{Sb}_{y} \mathrm{~N}_{z} / \mathrm{InP}$ is obtained after postgrowth high-temperature thermal annealing [80]. Unlike other dilute nitride alloys, there was no significant annealing-induced blue-shift of the optical transitions in the GaAsSbN/InP MQWs, which confirms the theoretical expectation that a change in the nearest neighbor configuration nitrogen atoms has negligible effect on bandgap of GaAsSbN [81]. Growth optimization of these materials in the type II QW heterostructures could lead to mid-IR sources based on wellestablished InP technology.

\section{CONCLUSION}

GaInNAs/GaAsSb and GaNAs/GaAsSb dilute nitride type II QWs have been grown by MOCVD and characterized through PL and EL measurements. RT PL measurements indicate that $\lambda \sim 1.5 \mu \mathrm{m}$ can be achieved, in good agreement with theory. Thermal annealing results in improved PL intensity, although at the expense of a significant emission wavelength blue-shift. Given the material strain limitation, design studies suggest that a dilute nitride type II QW design is a promising candidate to achieve $1.5 \mu \mathrm{m}$ laser emission on GaAs substrates and $>2 \mu \mathrm{m}$ laser emission on InP substrates, provided nonradiative recombination can be minimized through material optimization. Preliminary data on the incorporation of two- and three-stage dilute nitride "W"-active regions into diode lasers reveal a shorter lasing wavelength of $\sim 1.1-1.2 \mu \mathrm{m}$, as a result of transitions from higher energy states in addition to the wavelength blue-shift induced by charge separation within the active region. A design incorporating an increased number of stages is expected to lead to higher optical gain, required to achieve ground state lasing and minimize the emission wavelength blue-shift due to charge separation in the type II QW.

\section{ACKNOWLEDGMENT}

The authors would like to thank John Fournelle at the University of Wisconsin-Madison for electron probe micro-analyzer (EPMA) characterization, and J. Meyer and I. Vurgaftman [U.S. Naval Research Laboratory (NRL)] for technical support with the simulation studies. This work was funded by the Army Research Office.

\section{REFERENCES}

[1] S. Sato and S. Satoh, "1.21 $\mu \mathrm{m}$ continuous-wave operation of highly strained GaInAs quantum well lasers on GaAs substrates," Jpn. J. Appl. Phys., vol. 38, pp. 1990-1992, 1999.

[2] W. Choi, P. Daniel Dapkus, and J. J. Jewell, "1.2-mm GaAsP/InGaAs strain compensated single-quantum well diode laser on GaAs using metalorganic chemical vapor deposition," IEEE Photon. Technol. Lett., vol. 11, no. 12, pp. 1572-1574, Dec. 1999.

[3] N. Tansu, J. Y. Yeh, and L. J. Mawst, "Extremely-low threshold-currentdensity InGaAs quantum well lasers with emission wavelength of 12151233 nm," Appl. Phys. Lett., vol. 82, no. 23, pp. 4038-4040, Jun. 2003.

[4] P. Sundgren, J. Berggren, P. Goldman, and M. Hammar, "Highly strained InGaAs/GaAs multiple quantum-wells for laser applications in the 
1200-1300 nm wavelength regime," Appl. Phys. Lett., vol. 87, pp. 0711041-071104-3, 2005 .

[5] D. L. Huffaker, G. Park, Z. Zou, O. B. Shchekin, and D. G. Deppe, "1.3 $\mathrm{mm}$ room temperature GaAs-based quantum-dot laser," Appl. Phys. Lett., vol. 73, pp. 2564-2566, 1998.

[6] D. Bimberg, N. Kirstaedter, N. N. Ledentsov, Zh. I. Alferov, P. S. Kop'ev, and V. M. Ustinov, "InGaAs-GaAs quantum dot lasers," IEEE J. Sel. Topics Quantum Electron., vol. 3, no. 2, pp. 196-205, Apr. 1997.

[7] A. Stintz, G. T. Liu, H. Li, L. F. Lester, and K. J. Malloy, "Lowthreshold current density $1.3-\mathrm{mm}$ quantum-dot lasers with the dots-ina-well (DWELL) structure," IEEE Photon. Technol. Lett., vol. 12, no. 6, pp. 591-593, Jun. 2000.

[8] S. W. Ryu and P. D. Dapkus, "Low threshold current density GaAsSb quantum well $(\mathrm{QW})$ lasers grown by metal organic chemical vapour deposition on GaAs substrates," Electron. Lett., vol. 36, no. 16, pp. 1387-1388, 1999.

[9] T. Anan, K. Nishi, S. Sugou, M. Yamada, K. Tokutome, and A. Gomyo, "GaAsSb: A novel material for $1.3 \mathrm{~mm}$ VCSELs," Electron. Lett., vol. 34, no. 22, pp. 2127-2129, 1998.

[10] O. Blum and J. F. Klem, "Characteristics of GaAsSb single-quantum-welllasers emitting near $1.3 \mathrm{~mm}$," IEEE Photon. Technol. Lett., vol. 12, no. 7, pp. 771-773, Jul. 2000.

[11] I.-L. Chen, W.-C. Hsu, T.-D. Lee, and C.-H. Chiou, "Low threshold current density, highly strained InGaAs laser grown by MOCVD," Thin Solid Films, vol. 515, pp. 4522-4525, 2007.

[12] F. Bugge, U. Zeimer, R. Staske, B. Sumpf, G. Erbert, and M. Weyers, "MOVPE growth optimization for laser diodes with highly strained InGaAs MQWs," J. Cryst. Growth, vol. 298, pp. 652-657, 2007.

[13] M. Kondow, T. Kitatani, S. Nakatsuka, M. C. Larson, K. Nakahara, Y. Yazawa, M. Okai, and K. Uomi, "GaInNAs: A novel material for long wavelength semiconductor lasers," IEEE J. Sel. Topics Quantum Electron., vol. 3, no. 3, pp. 719-730, Jun. 1997.

[14] S. Sato and S. Satoh, "Room-temperature continuous-wave operation of 1.24-mm GaInNAs lasers grown by metal-organic chemical vapor deposition," IEEE J. Sel. Topics Quantum Electron., vol. 5, no. 3, pp. 707-710, May/Jun. 1999.

[15] F. Hohnsdorf, J. Koch, S. Leu, W. Stolz, B. Borchert, and M. Druminski, "Reduced threshold current densities of (GaIn)(Nas)/GaAs single quantum well lasers for emission wavelengths in the range 1.28-1.38 $\mu \mathrm{m}$," Electron. Lett., vol. 35, no. 7, pp. 571-572, 1999.

[16] B. Borchert, A. Y. Egorov, S. Illek, and H. Riechert, "Static and dynamics characteristics of $1.29 \mathrm{~mm}$ GaInNAs ridge-waveguide laser diodes," IEEE Photon. Technol. Lett., vol. 12, no. 6, pp. 597-599, Jun. 2000.

[17] M. R. Gokhale, P. V. Studenkov, J. Wei, and S. R. Forrest, "Low-threshold current, high efficiency $1.3-\mu \mathrm{m}$ wavelength aluminium-free InGaAsNbased quantum-well lasers," IEEE Photon. Technol. Lett., vol. 12, no. 2, pp. 131-133, Feb. 2000.

[18] K. D. Choquette, J. F. Klem, A. J. Fischer, O. Blum, A. A. Allerman, I. J. Fritz, S. R. Kurtz, W. G. Breiland, R. Sieg, K. M. Geib, J. W. Scott, and R. L. Naone, "Room temperature continuous wave InGaAsN quantum well vertical-cavity lasers emitting at $1.3 \mathrm{~mm}$," Electron. Lett., vol. 36, no. 16, pp. 1388-1390, 2000.

[19] N. Tansu, N. J. Kirsch, and L. J. Mawst, "Low-threshold-current-density 1300-nm dilute-nitride quantum well lasers," Appl. Phys. Lett., vol. 81, no. 14, pp. 2523-2525, Sep. 2002.

[20] Y. Qu, C. Y. Liu, and S. Yuan, "High-power 1.3-mm InGaAsN straincompensated lasers fabricated with pulsed anodic oxidation," Appl. Phys. Lett., vol. 85, pp. 5149-5151, 2004.

[21] F. Koyama, D. Schlenker, T. Miyamoto, Z. Chen, A. Matsutani, T. Sakaguchi, and K. Iga, " $1.2 \mathrm{~mm}$ highly strained GaInAs/GaAs quantum well lasers for single mode fibre datalink," Electron. Lett., vol. 35, no. 13, pp. 1079-1081, 1999 .

[22] D. Schlenker, T. Miyamoto, Z. Chen, F. Koyama, and K. Iga, "1.17mm highly strained GaInAs-GaAs quantum-well laser," IEEE Photon. Technol. Lett., vol. 11, no. 8, pp. 946-948, Aug. 1999.

[23] N. Tansu and L. J. Mawst, "High-performance, strain compensated InGaAs-GaAsP-GaAs $(l=1.17 \mathrm{~mm})$ quantum well diode lasers," IEEE Photon. Technol. Lett., vol. 13, no. 3, pp. 179-181, Mar. 2001.

[24] T. Takeuchi, Y.-L. Chang, A. Tandon, D. Bour, S. Corzine, R. Twist, M. Tan, and H.-C. Luan, "Low threshold $1.2 \mathrm{~mm} \mathrm{InGaAs} \mathrm{quantum} \mathrm{well}$ lasers grown under low As/III ratio," Appl. Phys. Lett., vol. 80, no. 14, pp. 2445-2447, Apr. 2002.

[25] S. Mogg, N. Chitica, R. Schatz, and M. Hammar, "Properties of highly strained InGaAs/GaAs quantum wells for 1.2- $\mu \mathrm{m}$ laser diodes," Appl. Phys. Lett., vol. 81, pp. 2334-2336, 2002.
[26] N. Tansu, J. Y. Yeh, and L. J. Mawst, "High-performance 1200-nm InGaAs and $1300-\mathrm{nm}$ InGaAsN quantum well lasers by metalorganic chemical vapor deposition," IEEE J. Sel. Topics Quantum Electron., vol. 9, no. 5, pp. 1220-1227, Sep./Oct. 2003.

[27] J. Yeh, L. J. Mawst, and N. Tansu, "Characteristics of InGaAsN/GaAsN QW lasers in the 1.4 micron regime," J. Cryst. Growth, vol. 272, pp. 719725, Jun. 2004

[28] N. Tansu, J.-Y. Yeh, and L. J. Mawst, "Physics and characteristics of high performance $1200 \mathrm{~nm}$ InGaAs and 1300-1400 nm InGaAsN QW lasers obtained by MOCVD," J. Phys.: Condens. Matter, vol. 16, pp. S3277S3318, 2004.

[29] D. J. Palmer, P. M. Smowton, P. Blood, J. Yeh, N. Tansu, and L. J. Mawst, "The effect of nitrogen on the gain and efficiency in InGAsN QW lasers," Appl. Phys. Lett., vol. 86, pp. 071121-1-071121-3, 2005.

[30] H. Shimizu, K. Kumada, S. Uchiyama, and A. Kasukawa, "Highperformance CW $1.26-\mu \mathrm{m}$ GaInNAsSb-SQW ridge lasers," IEEE $J$. Quantum Electron., vol. 7, no. 2, pp. 355-364, Mar./Apr. 2003.

[31] S. R. Bank, M. A. Wistey, H. B. Yuen, L. L. Goddard, W. Ha, and J. S. Harris, "Low-threshold CW GaInNAsSb/GaAs laser at $1.49 \mu \mathrm{m}$," Electron. Lett., vol. 39, pp. 1445-1446, 2003.

[32] N. Tansu and L. J. Mawst, "Design analysis of 1550-nm GaAsSb(In)GaAsN Type-II quantum well laser active regions," IEEE J. Quantum Electron., vol. 39, no. 10, pp. 1205-1210, Oct. 2003.

[33] I. Vurgaftman, J. R. Meyer, N. Tansu, and L. J. Mawst, "(In)GaAsNGaAsSb Type-II "W" quantum-well lasers for emission at $\lambda=1.55 \mu \mathrm{m}$," Appl. Phys. Lett., vol. 83, no. 14, pp. 2742-2744, Oct. 2003.

[34] I. Vurgaftman, J. R. Meyer, N. Tansu, and L. J. Mawst, "InP-based dilutenitride mid-infrared type-II 'W' quantum-well lasers," J. Appl. Phys., vol. 96, no. 8, pp. 4653-4655, Oct. 2004.

[35] J. Y. T. Huang, D. P. Xu, L. J. Mawst, T. F. Kuech, I. Vurgaftman, and J. R. Meyer, "GaAsSbN-GaAsSb-InP Type-II "W" quantum wells for mid-IR emission," IEEE J. Sel. Topics Quantum Electron., vol. 13, no. 5, pp. 1065-1073, Sep./Oct. 2007.

[36] J. R. Meyer, C. A. Hoffman, F. J. Bartoli, and L. R. Ram-Mohan, "Type-II quantum-well lasers for the mid-wavelength infrared," Appl. Phys. Lett., vol. 67, no. 6, pp. 757-759, 7 Aug. 1995.

[37] W. W. Bewley, C. L. Felix, I. Vurgaftman, D. W. Stokes, E. H. Aifer L. J. Olafsen, J. R. Meyer, M. J. Yang, B. V. Shanabrook, H. Lee, R. U. Martinelli, and A. R. Sugg, "High-temperature continuous-wave 3-6.1 $\mu \mathrm{m}$ " $\mathrm{W}$ " lasers with diamond-pressure-bond heat sinking," Appl. Phys. Lett., vol. 74, pp. 1075-1077, 1999.

[38] R. Kaspi, A. P. Ongstad, G. C. Dente, J. R. Chavez, M. L. Tilton, and D. M. Gianardi, "High performance optically pumped antimonide lasers operating in the 2.4-9.3 $\mu$ m wavelength range," Appl. Phys. Lett., vol. 88, no. 4, pp. 041122-1-041122-3, Jan. 2006.

[39] C. L. Canedy, W. W. Bewley, C. S. Kim, M. Kim, J. R. Lindle, I. Vurgaftman, and J. R. Meyer, "CW midinfrared "W" diode and interband cascade lasers," J. Vac. Sci. Technol. B, vol. 24, pp. 1613-1615, May 2006.

[40] P. Dowd, W. Braun, D. J. Smith, C. M. Ryu, C.-Z. Guo, S. L. Chen, U. Koelle, S. R. Johnson, and Y.-H. Zhang, "Long wavelength (1.3 and $1.5 \mathrm{~mm}$ ) photoluminescence from InGaAs/GaPAsSb quantum wells grown on GaAs," Appl. Phys. Lett., vol. 75, no. 9, pp. 1267-1269, 1999.

[41] M. Kudo, K. Ouchi, J. I. Kasai, and T. Mishima, "Low-lattice-strain longwavelength $\mathrm{GaAsSb} / \mathrm{GaInAs}$ Type-II quantum wells grown on GaAs substrates," Jpn. J. Appl. Phys., vol. 41, pp. L1040-L1042, 2002.

[42] S. W. Ryu and P. D. Dapkus, "Room temperature operation of type-II GaAsSb/InGaAs quantum well laser on GaAs substrates," Electron. Lett., vol. 38 , no. 12 , pp. $564-565,2002$.

[43] J. R. Meyer, C. L. Felix, W. W. Bewley, I. Vurgaftman, E. H. Aifer, L. J. Olafsen, J. R. Lindle, C. A. Hoffman, M.-J. Yang, B. R. Bennett, B. V. Shanabrook, H. Lee, C.-H. Lin, S. S. Pei, and R. H. Miles, "Auger coefficients in type-II InAs/Ga $\mathrm{Ga}_{1-x} \mathrm{In}_{x}$ Sb quantum wells," Appl. Phys. Lett., vol. 73, pp. 2857-2859, 1998.

[44] I. Vurgaftman, J. R. Meyer, N. Tansu, and L. J. Mawst, "InP-based dilutenitride mid-infrared type-II "W" quantum-well lasers," J. Appl. Phys., vol. 96, no. 8, pp. 4653-4655, Oct. 2004.

[45] M. J. Ekenstedt, S. M. Wang, and T. G. Andersson, "Temperaturedependent critical layer thickness for In $0.36 \mathrm{Ga} 0.64 \mathrm{As} / \mathrm{GaAs}$ single quantum wells," Appl. Phys. Lett., vol. 58, pp. 854-855, 1991.

[46] H. H. Tan, P. Lever, and C. Jagadish, "Growth of highly strained InGaAs quantum wells on GaAs substrates-Effect of growth rate," J. Cryst. Growth, vol. 274, pp. 85-89, 2005.

[47] R. E. Welser, R. S. Setzko, K. S. Stevens, E. M. Rehder, C. R. Lutz, D. S. Hill, and P. J. Zampardi, "Minority carrier properties of carbon-doped 
GaInAsN bipolar transistors," J. Phys.: Condens. Matter, vol. 16, pp. S3373-S3385, 2004.

[48] B. E. Hawkins, A. A. Khandekar, J. Y. Yeh, L. J. Mawst, and T. F. Kuech, "Effects of gas switching sequences on GaAs/GaAs1-Sb-y(y) superlattices," J. Cryst. Growth, vol. 272, no. 1-4, pp. 686-693, Dec. 2004.

[49] J. Y. Yeh, L. J. Mawst, A. A. Khandekar, T. F. Kuech, I. Vurgaftman, J. R. Meyer, and N. Tansu, "Characteristics of InGaAsN-GaASSb type-II "W" quantum wells," J. Cryst. Growth, vol. 287, pp. 615-619, 2006.

[50] J.-Y. Yeh, L. J. Mawst, A. A. Khandekar, T. F. Kuech, I. Vurgaftman, J. R. Meyer, and N. Tansu, "Long wavelength emission of InGaAsN/GaAsSb Type-II "W" quantum wells," Appl. Phys. Lett., vol. 88, pp. 051115-1-051115-3, 2006.

[51] X. Yang, J. B. Heroux, M. J. Jurkovic, and W. I. Wang, "Photoluminescence of as-grown and thermally annealed InGaAsN/GaAs quantum wells grown by molecular beam epitaxy," J. Vac. Sci. Technol. B, vol. 17, no. 3, pp. 1144-1146, 1999.

[52] Y. Fedorenko, T. Jouhti, E. M. Pavelescu, S. Karirinne, J. Kontinnen, and M. Pessa, "Optimisation of growth temperature and post-growth annealing for GaInNAs/GaNAs/GaAs quantum-well structures emitting at $1.3 \mu \mathrm{m}$," Thin Solid Films, vol. 440, pp. 195-197, 2003.

[53] G. Mussler, L. Daweritz, K. H. Ploog, J. W. Tomm, and V. Talalaev, "Optimized annealing conditions identified by analysis of radiative recombination in dilute Ga(As,N)," Appl. Phys. Lett., vol. 83, pp. 1343-1345, 2003.

[54] T. Kageyama, T. Miyamoto, S. Makino, F. Koyama, and K. Iga, "Optical quality of GaNAs and GaInNAs and its dependence on RF cell condition in chemical beam epitaxy,” Jpn. J. Appl. Phys., vol. 38, pp. L298-L300, 1999.

[55] R. Kudrawiec, G. Sek, J. Misiewicz, D. Gollub, and A. Forchel, "Explanation of annealing-induced blueshift of the optical transitions in GaInAsN/GaAs quantum wells," Appl. Phys. Lett., vol. 83, pp. 27722774, 2003.

[56] V. Lordi, V. Gambin, S. Friedrich, T. Funk, T. Takizawa, K. Uno, and J. S. Harris, "Nearest-neighbor configuration in (GaIn)(NAs) probed by X-ray absorption spectroscopy," Phys. Rev. Lett., vol. 90, pp. 145505-1145505-4, 2003

[57] M. Albrecht, V. Grillo, T. Remmele, H. P. Strunk, A. Y. Egorov, G. Dumitras, H. Riechert, A. Kaschner, R. Heitz, and A. Hoffmann, "Effect of annealing on the In and $\mathrm{N}$ distribution in InGaAsN quantum wells," Appl. Phys. Lett., vol. 81, pp. 2719-2721, 2002.

[58] V. Gambin, V. Lordi, W. Ha, M. Wistey, T. Takizawa, K. Uno, S. Friedrich, and J. Harris, "Structural changes on annealing of MBE grown (Ga, In) (N, As) as measured by X-ray absorption fine structure," J. Cryst. Growth, vol. 251, pp. 408-411, 2003.

[59] H. P. Xin, K. L. Kavanagh, M. Kondow, and C. W. Tu, "Effects of rapid thermal annealing on GaInNAs/GaAs multiple quantum wells," J. Cryst. Growth, vol. 201/202, pp. 419-422, 1999.

[60] W. W. Chow, O. B. Spahn, H. C. Schneider, and J. F. Klem, "Contributions to the large blue emission shift in a GaAsSb type-II laser," IEEE J. Quantum Electron., vol. 37, no. 9, pp. 1178-1182, Sep. 2001.

[61] S.-H. Park, "Electronic and optical properties of type-II GaAsSb/GaInAs/GaAs trilayer quantum-well lasers," J. Korean Phys. Soc., vol. 46, no. 4, pp. 835-839, 2005.

[62] J. F. Klem, O. Blum, S. R. Kurtz, I. J. Fritz, and K. D. Choquette, "GaAsSb/InGaAs type-II quantum wells for long-wavelength lasers on GaAs substrates," J. Vac. Sci. Technol. B, vol. 18, pp. 1605-1608, 2000.

[63] R. Teissier, D. Sicault, J. C. Harmand, G. Ungaro, G. Le Roux, and L. Largeau, "Temperature-dependent valence band offset and band-gap energies of pseudomorphic GaAsSb on GaAs," J. Appl. Phys., vol. 89, pp. 5473-5477, 2001.

[64] N. Nuntawong, Y. C. Xin, S. Birudavolu, P. S. Wong, S. Huang, C. P. Hains, and D. L. Huffaker, "Quantum dot lasers based on a stacked and straincompensated active region grown by metal-organic chemical vapor deposition," Appl. Phys. Lett., vol. 86, pp. 193115-1-193115-3, 2005.

[65] P. D. Dapkus, International patent application no. PCT/US00/14332 (WO01/29943), May 24, 2000.

[66] A. A. Khandekar, B. E. Hawkins, T. F. Kuech, J. Y. Yeh, L. J. Mawst, J. R. Meyer, I. Vurgaftman, and N. Tansu, "Characteristics of GaAsN/GaAsSb type-II quantum wells grown by metalorganic vapor phase epitaxy on GaAs substrates," J. Appl. Phys., vol. 98, pp. 1235251-123525-5, 2005.

[67] H. Mani, A. Joullie, F. Karouta, and C. Schiller, "Low-temperature phase diagram of the Ga-As-Sb system and liquid-phase-epitaxial growth of lattice-matched GaAsSb on (100) InAs substrates," J. Appl. Phys., vol. 59, pp. 2728-2734, 1986.
[68] O. J. Pitts, S. P. Watkins, C. X. Wang, V. Fink, and K. L. Kavanagh, "Antimony segregation in GaAs-based multiple quantum well structures," J. Cryst. Growth, vol. 254, pp. 28-34, 2003.

[69] A. A. Khandekar, J. Y. Yeh, L. J. Mawst, X. Song, S. E. Babcock, and T. F. Kuech, "Effects of Ga- and Sb-precursor chemistry on the alloy composition in pseudomorphically strained $\mathrm{GaAs}_{1-y} \mathrm{Sb}_{y}$ films grown via metalorganic vapor phase epitaxy," J. Cryst. Growth, vol. 303, pp. 456465, 2007.

[70] J. D. Thomson, P. M. Smowton, P. Blood, and J. F. Klem, " "Optical gain and spontaneous emission in GaAsSb-InGaAs Type-II "W" laser structures," IEEE J. Quantum Electron., vol. 43, no. 7, pp. 607-613, Jul. 2007.

[71] J. G. Kim, L. Shterengas, R. U. Martinelli, and G. L. Belenky, "Highpower room-temperature continuous wave operation of 2.7 and $2.8 \mu \mathrm{m}$ In(Al)GaAsSb/GaSb diode lasers," Appl. Phys. Lett., vol. 83, no. 10, pp. 1926-1928, Sep. 2003.

[72] M. Grau, C. Lin, O. Dier, and M.-C. Amann, "Continuous-wave GaInAsSb/AlGaAsSb type-I double quantum well lasers for $2.96 \mu \mathrm{m}$ wavelength," Electron. Lett., vol. 39, pp. 1816-1817, Dec. 2003.

[73] M. Grau, C. Lin, O. Dier, C. Lauer, and M.-C. Amann, "Room-temperature operation of $3.26 \mu \mathrm{m}$ GaSb-based type-I lasers with quinternary AlGaInAsSb barriers," Appl. Phys. Lett., vol. 87, no. 24, pp. 2411041-241104-3, Dec. 2005.

[74] S. Forouhar, A. Ksendzov, A. Larson, and H. Temkin, "InGaAs/InGaAsP/InP strained-layer quantum well lasers at $\sim 2 \mu \mathrm{m}$," Electron. Lett., vol. 28, pp. 1431-1432, Jul. 1992.

[75] M. Peter, R. Kiefer, F. Fuchs, N. Herres, K. Winkler, K.-H. Bachem, and J. Wagner, "Light-emitting diodes and laser diodes based on a $\mathrm{Ga}_{1-x} \mathrm{In}_{x} / \mathrm{GaAs}_{1-y} \mathrm{Sb}_{y}$ type II superlattice on InP substrate," Appl. Phys. Lett., vol. 74, no. 14, pp. 1951-1953, Apr. 1999.

[76] G. M. Peake, K. E. Waldrip, T. W. Hargett, N. A. Modine, and D. K. Serkland, "OMVPE of GaAsSbN for long wavelength emission on GaAs," J. Cryst. Growth, vol. 261, pp. 398-403, 2004.

[77] J. Y. T. Huang, D. P. Xu, J. H. Park, L. J. Mawst, T. F. Kuech, X. Song, S. E. Babcock, I. Vurgaftman, and J. R. Meyer, "Characteristics of strained $\mathrm{GaAs}_{1-y} \mathrm{Sb}_{y}(0.16 \leq \mathrm{y} \leq 0.69)$ quantum wells on InP substrates," J. Phys. D: Appl. Phys., vol. 40, pp. 7656-7661, 2007.

[78] D. P. Xu, J. Y. T. Huang, J. H. Park, L. J. Mawst, T. F. Kuech, I. Vurgaftman, and J. R. Meyer, "Characteristics of dilute-nitride GaAsSbN/InP strained multiple quantum wells," Appl. Phys. Lett., vol. 90, pp. 171913-1-1719133, 2007.

[79] J. Y. T. Huang, D. P. Xu, X. Song, S. E. Babcock, T. F. Kuech, and L. J. Mawst, "Growth of strained $\mathrm{GaAs}_{1-y} \mathrm{Sb}_{y}$ and $\mathrm{GaAs}_{1-y-z} \mathrm{Sb}_{y} \mathrm{~N}_{z}$ quantum wells on InP substrates," J. Cryst. Growth, to be published.

[80] D. P. Xu, J. Y. T. Huang, J. H. Park, L. J. Mawst, T. F. Kuech, X. Song, and S. E. Babcock, "Annealing of dilute-nitride GaAsSbN/InP strained multiple quantum wells," Appl. Phys. Lett., vol. 91, pp. 191909-1-1919093, 2007.

[81] J.-C. Harmand, A. Caliman, E. V. K. Rao, L. Largeau, J. Ramos, R. Teissier, L. Travers, G. Ungaro, B. Theys, and I. F. L. Dias, "GaNAsSb: How does it compare with other dilute III-V-nitride alloys?," Semicond. Sci. Technol., vol. 17, pp. 778-784, 2002.

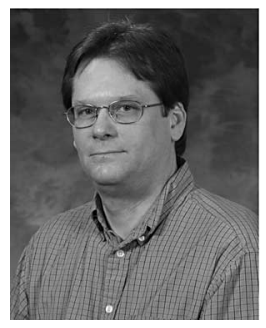

L. J. Mawst (M'88-SM'93) was born in Chicago, IL, in 1959. He received the B.S. degree in engineering physics and the M.S. and Ph.D. degrees in electrical engineering from the University of Illinois at UrbanaChampaign, Urbana-Champaign, in 1982, 1984, and 1987, respectively.

In 1987, he joined TRW, Inc., Redondo Beach, CA, where he was a Senior Scientist in the Research Center, and was engaged in design and development of semiconductor lasers using metal-organic chemical vapor deposition (MOCVD) crystal growth. He is the coinventor of the resonant optical waveguide (ROW) antiguided array and has contributed to its development as a practical source of high coherent power. He developed a novel single-mode edge-emitting laser structure, the ARROW laser, as a source for coupling high powers into fibers. He is currently a Professor in the Electrical and Computer Engineering Department, University of Wisconsin-Madison, Madison, where he is involved in the development of novel III/V compound semiconductor device structures, including vertical-cavity surface emitters (VCSELs), active photonic lattice structures, InGaAsN lasers, and high-power Al-free diode lasers. His current research on low-temperature MOCVD-grown highly strained InGaAs and InGaAsN led to record low threshold current density diode lasers. He is the author or coauthor of more than 175 technical papers and holds 19 patents.

Prof. Mawst received the TRW Group Level Chairman's Award. 




Juno Yu-Ting Huang (S'06) received the B.S. and M.S. degrees in chemical engineering in 1998 and 2000 , respectively, and the Diploma in composite materials in 2000 from the National Cheng Kung University, Tainan, Taiwan, R.O.C. She is currently working toward the Ph.D. degree in electrical and computer engineering at the University of Wisconsin-Madison, Madison.

In 2000, she joined Applied Materials, Inc. In September 2005, she joined Prof. Luke Mawst's Research Group, University of Wisconsin-Madison. Her current research interests include the study of quantum well lasers and detectors for the near-infrared and mid-infrared regions.

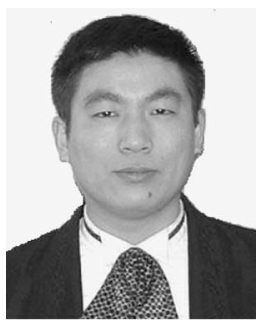

D. P. Xu received the B.S. degree in applied physics from Dalian University of Technology, Dalian, China, in 1995, and the Ph.D. degree in optoelectronics and microelectronics from the Chinese Academy of Sciences, Institute of Semiconductors, Beijing, China, in 2000 .

He was with the Department of Electrical and Computer Engineering, University of WisconsinMadison, Madison. His current research interests include the development of quantum cascade laser, dilute-nitride-based materials, type II quantum well lasers, and GaN-based LEDs and lasers by metal-organic chemical vapor deposition (MOCVD).



Jeng-Ya Yeh received the B.S. degree in physics from the National Tsing Hua University, Hsinchu, Taiwan, R.O.C., in 1996, and the Ph.D. degree in electrical and computer engineering from the University of Wisconsin-Madison, Madison, in 2005.

He is currently with Intel, Inc., Oregon, WA. His current research interests include developing high-performance long-wavelength ( $1300 \mathrm{~nm}$ and beyond) InGaAsN quantum well (QW) lasers by metalorganic chemical vapor deposition (MOCVD) for optical communication, optimization, and physical understanding of the lasing characteristics of InGaAsN QW lasers.

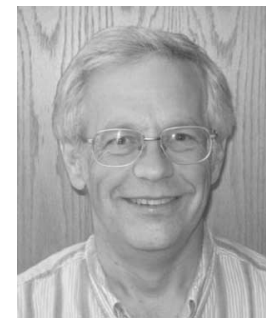

Thomas F. Kuech (S'79-M'81) received the B.S degree in physics and the M.S. degree in materials science in 1976 and 1977, respectively, both from Marquette University, Milwaukee, WI, and the second M.S. and Ph.D. degrees in applied physics from the California Institute of Technology, Pasadena, in 1977 and 1981, respectively.

Since 1990, he has been with the Department of Chemical and Biological Engineering, University of Wisconsin-Madison, Madison, where he is currently the Shoemaker Professor of Chemical Engineering. From 1981 to 1990, he was a Research Staff Member at the IBM T. J. Watson Research Center, Yorktown Heights, NY. He is the author or coauthor of several research papers published in the fields of epitaxial growth, transport properties of Schottky barriers, ohmic contacts, and heteroepitaxial structures, nonstoichiometric ceramic oxides, and the solid-state properties of semiconductor materials. His current research interests include the chemical and physical processes underlying the synthesis of semiconductor materials and structures.

Nelson Tansu was born in October 1977. He received the B.S. degree in applied mathematics, electrical engineering, and physics with highest distinction and the Ph.D. degree in electrical engineering from the University of WisconsinMadison, Madison, in 1998 and 2003, respectively.

Since July 2003, he has been an Assistant Professor in the Department of Electrical and Computer Engineering (ECE) and the Center for Optical Technologies (COT), Lehigh University, Bethlehem, PA, where, since April 2007, he has also been the Peter C. Rossin Assistant Professor of Electrical and Computer Engineering. His current research interests include the theoretical and experimental aspects of the physics of semiconductor optoelectronics materials and devices, the physics of low-dimensional semiconductor (nanostructure), and metal-organic chemical vapor deposition (MOCVD) epitaxy and device fabrications of III-V-nitride and III-nitride semiconductor optoelectronics devices on $\mathrm{GaAs}, \mathrm{InP}$, and $\mathrm{GaN}$ substrates. His teaching interests are in the areas of optoelectronics and photonics, semiconductor physics, applied quantum mechanics, and engineering electromagnetism. He is the author or coauthor of more than 119 papers published widely in numerous refereed international journal and conference publications. He also holds several U.S. patents. He has given more than 30 lectures, seminars, and invited talks in universities, research institutions, and conferences in USA, Canada, Europe, and Asia.

Dr. Tansu had served several times as a panel member for the US National Science Foundation, the US Department of Defense, and other agencies in USA and abroad. He was a recipient of the Bohn Scholarship, the WARF Graduate University Fellowship, the Vilas Graduate University Fellowship, and the Graduate Dissertator Travel Funding Award, and the 2003 Harold A. Peterson ECE Best Research Award (1st Prize) at the University of Wisconsin-Madison.



Gene Tsvid was born in Moscow, Russia, in 1975. He received the M.S. degree in physics from Moscow Institute of Physics and Technology in 1998. He is currently working toward the Ph.D. degree at the University of Wisconsin-Madison, Madison.

$\mathrm{He}$ is currently a Research Assistant at the University of Wisconsin-Madison, where he is involved in development and characterization of novel semiconductor device structures including interband quantum dot systems, type I and type II quantum well systems, and unipolar intersubband quantum cascade and quantum box laser media. 